\title{
ARCH Models for Multi-period Forecast Uncertainty -A Reality Check Using a Panel of Density Forecasts
}

by

\author{
Kajal Lahiri and Fushang Liu \\ Department of Economics \\ University at Albany - SUNY \\ Albany, NY 12222. USA \\ Email:klahiri@albany.edu
}




\title{
ARCH Models for Multi-period Forecast Uncertainty -A Reality Check Using a Panel of Density Forecasts
}

\author{
Kajal Lahiri and Fushang Liu
}

\begin{abstract}
We develop a theoretical framework to compare forecast uncertainty estimated from time series models to those available from survey density forecasts. The sum of the average variance of individual densities and the disagreement, which is the same as the variance of the aggregate density, is shown to approximate the predictive uncertainty from well specified time series models when the variance of the aggregate shocks is relatively small compared to that of the idiosyncratic shocks. We argue that due to grouping error problems, compositional effects of the panel, and other complications, the uncertainty measure has to be estimated from individual densities. Despite numerous reservations on the credibility of time series based measures of forecast uncertainty, we found that during normal times the uncertainty estimates based on $\mathrm{ARCH}$ models simulate the subjective survey measure remarkably well. However, during times of regime change and structural break, the two estimates do not overlap. We suggest ways to improve the time series measures during periods when forecast errors are apt to be large. The disagreement series is a good indicator of such periods.
\end{abstract}

Keywords: Inflation, Survey of Professional Forecasters, GARCH, Real time data.

JEL:E31; E37; C23; C53 


\section{Introduction}

Macroeconomic uncertainty as characterized by aggregate forecast density or intervals has long been recognized as an important factor in determining economic outcomes. ${ }^{1}$ Milton Friedman, in his Nobel lecture (1977), conjectured that high inflation causes high inflation uncertainty, and that high uncertainty in turn causes inefficiencies in the economy. The latest Nobel laureate Robert Engle (1983) wrote while introducing his celebrated ARCH model,

"When inflation is unpredictable, risk averse economic agents will incur loss, even if prices and quantities are perfectly flexible in all markets. Inflation is a measure of the relative price of goods today and goods tomorrow; thus, uncertainty in tomorrow's price impairs the efficiency of today's allocation decisions."

Not surprisingly, these developments have triggered much research studying the effects of inflation uncertainty on savings, interest rates, investment, and other variables. More recently, the introduction of inflation targeting regimes in U.K., Canada, Sweden, and many other countries during the 1990s has rekindled an enormous interest in generating credible inflation forecasts and the uncertainty associated with the forecasts. ${ }^{2}$

In order to deal with the causes and consequences of forecast uncertainty in a convincing way, it has to be measured correctly. This is particularly important for predictive uncertainty because, unlike forecasts, variance of predictive errors generated by macro time series models is always unobserved, and hence, can never be evaluated against subsequently observed realizations. During last twenty years, the most popular approach to estimate forecast uncertainty has been the univariate or multivariate ARCH models initiated by Engle (1982, 1983), who modeled the conditional variance of inflation forecast error as an autoregressive conditional heteroskedastic (ARCH) process. Bollerslev (1986), Nelson (1991), Glosten et al. (1993) and others have generalized the

\footnotetext{
${ }^{1}$ Interval and probability forecasts have a longer track record in weather forecasts and sports picks.

2 See, for, instance, Sims (2002), Šmidková (2003), Cogley et al. (2003), and Garratt et al. (2003).
} 
basic $\mathrm{ARCH}$ model in various directions, and have found many applications in finance and economics.

There are, however, several possible reasons why ARCH-type models may not produce a reliable proxy for inflation uncertainty. First, the reliability of this measure depends on the reliability of the conditional mean and variance functions. This is why Engle (1982, 1983) had emphasized the need for various specification tests in these models. More generally, Rich and Tracy (2003) have questioned the use of conditional variance of a series which is essentially related to its ex post predictability as a measure of forecast uncertainty which is related to ex ante confidence of a prediction. Second, most ARCHtype models assume that the regime characterizing inflation and inflation uncertainty is invariant over time. This assumption may not be true due to structural breaks. Although some researchers have tried to rectify this deficiency (see, for example, Evans (1991), Evans and Wachtel (1993)), the success of these efforts relies on correctly specifying the structural break itself. Third, as noted by Bomberger (1996) and McNees (1989), forecasters use different models. Thus, uncertainty regarding the model that generates inflation may be a large part of inflation forecast uncertainty. Conditional variance generated by a single model cannot capture this important feature. Finally, Zarnowitz and Lambros (1987) observed that forecast uncertainty depends not only on past forecast errors but also on many future-oriented factors such as policy changes, macro shocks, data revisions and many others including purely subjective factors. ARCH-type models ignore this forward-looking behavior of forecasters and other relevant factors that are not included in the time series specification. ${ }^{3}$

In the U.S., research on the measurement of forecast uncertainty was facilitated by the foresight of Victor Zarnowitz who under the aegis of American Statistical Association and the National Bureau of Economic Research pioneered a survey in 1968 in which, apart from other point forecasts, subjective density forecasts of real GDP and inflation

\footnotetext{
${ }^{3}$ Sims (2002) discusses the current state and limitations of models generating macro forecasts and their uncertainty.
} 
were elicited from the survey respondents. ${ }^{4}$ The average variance of the individual probability distributions can then be directly used as a time series measure of forecast uncertainty. Studies that used this measure include, among others, Zarnowitz and Lambros (1987), Lahiri and Teigland (1987), Lahiri, Teigland and Zaporowski (1988) and Batchelor and Dua (1993). This measure is attractive because the variance associated with the density forecast truly represents the uncertainty perceived by an individual forecaster. Batchelor and Dua (1995) and Giordani and Soderlind (2003) argued that this measure reflects the uncertainty a reader of survey forecasts faces if he randomly picks and trusts one of the point forecasts. One question here is whether we should also include forecast disagreement across individuals as a component of aggregate uncertainty. Since forecast disagreement reflects people's uncertainty about models, arguably it should be a part of the aggregate forecast uncertainty. ${ }^{5}$

Due to its ready availability, the variance of the point forecasts (or disagreement) of the survey respondents has been widely used as a proxy for inflation uncertainty. For example, Levi and Makin (1978) and Makin (1983) used this measure to test a hypothesis about the relationship between inflation uncertainty and interest rates. Cukierman and Wachtel $(1979,1982)$ investigated the relationship between inflation uncertainty and inflation level as well as the variance of the change of relative prices. Although forecast disagreement is easy to compute, its disadvantages are obvious. First, individual biases may be part of forecast disagreement, which does not necessarily reflect forecast uncertainty. Secondly, as noted by Zarnowitz and Lambros (1987), it is possible that individual forecasters are extremely certain about their own forecasts, yet the forecasts themselves are substantially dispersed. Conversely, the forecast uncertainty of individual forecasts may be high but point forecasts may be close. Disagreement would then overstate uncertainty in the former case, and understate it in the latter.

\footnotetext{
${ }^{4}$ Since 1990 the Federal Reserve Bank of Philadelphia manages the survey, now called the Survey of Professional Forecasters (SPF).

${ }^{5}$ We could think of the model as a random variable. The set of individual models used by each forecaster is a sample of this random variable. Then forecast disagreement can be used to estimate the model uncertainty.
} 
There is rather a large literature comparing these three measures of predictive confidence. Engle (1983) was the first to discuss the relationship between the forecast uncertainty derived from the ARCH model and from survey data. He showed that the conditional variance is approximately equal to the average individual forecast error variance. Zarnowitz and Lambros (1987) found that although the average forecast error variance and forecast disagreement are positively correlated, the latter tends to be smaller than the former. Batchelor and Dua $(1993,1996)$ compared the average individual forecast error variance with a number of proxies including forecast standard deviations from ARIMA, $\mathrm{ARCH}$ and structural models of inflation. They found that these proxies are not significantly correlated with the average individual forecast error variance. Other related works include Bomberger (1996), Evans (1991) and Giordani and Soderlind (2003). However, one drawback common to most of these studies is that when comparing different measures of inflation uncertainty the supporting information sets were often not exactly the same. For example, forecasters in a survey often have more information than historical data. They have partial information about current period when making forecasts. So a direct comparison of forecast disagreement or average individual forecast variance with a time series measures may not be appropriate. Second, due to heterogeneity in forecasts, survey measures often have individual biases. When comparing survey measures with time series estimates, we should first correct for these compositional effects in the panel. Finally, most existing studies are empirical. We need a theoretical framework to compare estimates of uncertainty based on aggregate time series and survey data on forecast densities.

In this paper, we propose a simple model to characterize the data generating process in SPF. We argue that the estimated variance of the aggregate density as proposed by Diebold et al. (1999) and Wallis (2004) gives a reasonably close lower bound on the forecast uncertainty imbedded in a well-specified time series model. Since the former variance is simply the sum of average variance of the individual densities and the forecast disagreement (cf. Lahiri et al. (1988)), our model presents a way of justifying the use of 
disagreement as a component of macroeconomic uncertainty. ${ }^{6}$ Considering that time series models often have misspecification problems, the sum of forecast disagreement and average individual forecast error variance from surveys may provide a reasonable proxy for the aggregate forecast uncertainty over diverse periods. Our empirical analysis shows that the time series measure and survey measure are remarkably similar during periods of low and stable inflation. But during periods of high and unpredictable inflation, the two tend to diverge.

The remainder of the paper is organized as follows. In section 2, we introduce our theoretical model to compare time series and survey measures of inflation uncertainty. In section 3, we show how to extract the measure of forecast uncertainty from the SPF data as defined in section 2. Sections 4 and 5 describe the SPF forecast density data, and present estimates of inflation forecast uncertainty defined as the sum of average individual forecast error variance and forecast disagreement. In sections 6 and 7, we empirically compare the survey measures estimated in section 5 with those estimated from some popular ARCH models. Section 8 concludes the paper.

\section{The model}

In this section, we propose a model to study the relationship between measures of forecast uncertainty based on survey data and time series models. Giordani and Soderlind (2003) and Wallis (2004) have discussed how a panel of density forecasts should be used to generate forecast uncertainty representing the entire economy. However, they did not try to find the relationship between survey and time series measures of forecast uncertainty.

Consider the prediction of the log of current general price level, $p_{t}$, the actual of which is available only in period $t+1$. Suppose the information set of forecaster $z$ is $I_{t}(z)$. Then

\footnotetext{
${ }^{6}$ In recent research forecast heterogeneity has appeared prominently as a component of overall macroeconomic uncertainty. See, for instance, Kurz (2002), Carroll (2003), Mankiw et al. (2003), and Souleles (2004).
} 
the prediction of $p_{t}$ made by forecaster $z$ can be expressed as $E\left(p_{t} \mid I_{t}(z)\right)$. In period $t$, individual forecasters can obtain information from two sources. First, they have knowledge of the past history of the economy in terms of its macroeconomic aggregates. This aggregate information may, for instance, be collected from government publications. Often macro forecasts are generated and made publicly available by government agencies and also by private companies. We assume that this information is common to all forecasters as public information. ${ }^{7}$ Although public information does not permit exact inference of $p_{t}$, it does determine a "prior" distribution of $p_{t}$, common to all forecasters. We assume the distribution of $p_{t}$ conditional on the public information is $p_{t} \sim N\left(\bar{p}_{t}, \sigma^{2}\right)$. Secondly, since SPF forecasters usually make forecasts in the middle of the quarter for the current and the next year, they will invariably have some private information about $p_{t}$. Thus, while reporting the density forecasts, they have partial information about the first half of period $t$ although official report of $p_{t}$ would still not be available. This private information may take the form of data on relevant variables that are available at higher frequencies (e.g., CPI, unemployment, Blue Chip monthly forecasts, etc.) that individual forecasters may use and interpret at their discretions. More importantly, it will be conditioned by individual forecasters' experience and expertise in specific markets. A key feature of this private information is that it is a mixture of useful information about $p_{t}$ and some other idiosyncratic information that is orthogonal to $p_{t}{ }^{8}$ If we use $p_{t}(z)$ to denote the private information of forecaster $z$ about $p_{t}$, then $p_{t}(z)$ will be a function of $p_{t}$ and the idiosyncratic factor denoted also by $z$ with $z \sim N\left(0, \tau_{z}^{2}\right)$. For simplicity, we assume

$$
p_{t}(z)=p_{t}+z
$$

\footnotetext{
${ }^{7}$ For example, it is commonly believed that the USDA forecasts for agricultural prices are used as 'benchmark" by many private and public forecasters, see Irwin et al. (1994) and Kastens et al. (1998).

${ }^{8}$ Our formulation is also consistent with the evidence presented by Furher (1988) that survey data contain useful information not present in the standard macroeconomic data base.
} 
By definition, $z$ is distributed independent of $p_{t}$ and individual-specific information of other forecasters. Although forecaster $z$ knows $p_{t}(z)$, he is not sure about the relative size of $p_{t}$ and $z$. The problem for the individual is how to infer about $p_{t}$ from the public information and the private information, $p_{t}(z)$. This is a typical signal extraction problem. ${ }^{9}$

Using (2-1) it is easy to show that the distribution of $p_{t}$ conditional on both the public and private information is normal with mean

$$
E\left(p_{t} \mid I_{t}(z)\right)=E\left(p_{t} \mid p_{t}(z), \bar{p}_{t}\right)=\left(1-\theta_{z}\right) p_{t}(z)+\theta_{z} \bar{p}_{t}
$$

and variance $\theta_{z} \sigma^{2}$, where $\theta_{z}=\tau_{z}^{2} /\left(\tau_{z}^{2}+\sigma^{2}\right)$.

Consider an outside observer (or a central policy maker) who is to forecast the aggregate price level. The information available to him is only the available public information. He has no private information about period $t$ that can help him to better infer about $p_{t}$. However, he can make an unbiased point forecast of $p_{t}$ with available public information. Under mean squared error loss function, the optimal point forecast should be $\bar{p}_{t}$, with forecast uncertainty being $\sigma^{2}$. Note that this is just the forecast and forecast uncertainty from aggregate time series models if the mean equation were correctly specified.

The situation facing forecaster $z$ is different. He has both the public and private information. Given the information set $I_{t}(z)$, his point forecast of $p_{t}$ is (2-2) with the associated forecast uncertainty $\theta_{z} \sigma^{2}$. Following Wallis (2004), we can "mix" the

\footnotetext{
${ }^{9}$ In Lucas' signal extraction model $(1972,1973)$, this private information is assumed to be the price in market $z$. Kurz and Motolese (2001) use a similar decomposition.
} 
individual distributions to obtain an aggregate forecast distribution and its variance. On the other hand, we can obtain the average of individual forecast uncertainties of $p_{t}$ as

$$
\overline{\operatorname{Var}}=\frac{1}{N} \sum_{z} \operatorname{var}\left(p_{t} \mid I_{t}(z)\right)=\frac{1}{N} \sum_{z} \theta_{z} \sigma^{2}=\bar{\theta} \sigma^{2}
$$

where $N$ is the number of forecasters.

Since forecasters observe different $p_{t}(z)$, they will make different point forecasts. The forecast disagreement defined as the variance of point forecasts across individuals is ${ }^{10}$

$$
\begin{aligned}
& \text { Disag }=\frac{1}{N} \sum_{z}\left\{E\left(p_{t} \mid I_{t}(z)\right)-\frac{1}{N} \sum_{z} E\left(p_{t} \mid I_{t}(z)\right)\right\}^{2} \\
& \stackrel{p}{\longrightarrow} \frac{1}{N} \sum_{z} E_{z}\left\{E\left(p_{t} \mid I_{t}(z)\right)-E_{z}\left[E\left(p_{t} \mid I_{t}(z)\right)\right]\right\}^{2}=\frac{1}{N} \sum_{z} \operatorname{var}_{z}\left[E\left(p_{t} \mid I_{t}(z)\right]\right.
\end{aligned}
$$

By (2-2)

$$
\operatorname{var}_{z}\left[E\left(p_{t} \mid I_{t}(z)\right)\right]=\operatorname{var}_{z}\left[\left(1-\theta_{z}\right) p_{t}+\left(1-\theta_{z}\right) z+\theta_{z} \bar{p}_{t}\right]=\left(1-\theta_{z}\right)^{2} \tau_{z}^{2}
$$

So, the forecast disagreement can be approximated by $\frac{1}{N} \sum_{z}\left(1-\theta_{z}\right)^{2} \tau_{z}^{2}$ and the sum of average individual forecast uncertainty and forecast disagreement is approximately equal to

$$
\begin{aligned}
& \overline{\text { Var }}+\text { Disag }=\frac{1}{N} \sum_{z}\left(\theta_{z} \sigma^{2}+\left(1-\theta_{z}\right)^{2} \tau_{z}^{2}\right)=\frac{1}{N} \sum_{z}\left(\frac{\tau_{z}^{2} \sigma^{2}}{\sigma^{2}+\tau_{z}^{2}}+\frac{\sigma^{4} \tau_{z}^{2}}{\left(\sigma^{2}+\tau_{z}^{2}\right)^{2}}\right) \\
& =\frac{1}{N} \sum_{z} \frac{2 \tau_{z}^{2} \sigma^{4}+\tau_{z}^{4} \sigma^{2}}{\left(\sigma^{2}+\tau_{z}^{2}\right)^{2}}=\sigma^{2} \frac{1}{N} \sum_{z}\left[1-\left(1-\theta_{z}\right)^{2}\right] \leq \sigma^{2}
\end{aligned}
$$

since $0 \leq \theta_{z} \leq 1$.

\footnotetext{
${ }^{10}$ Sample variance will converge in probability to the average of population variance. See Greene (2000), page 504.
} 
Equation (2-6) shows the relationship between the sum of the average individual forecast error variance and the forecast disagreement with the forecast uncertainty estimated from a well-specified time series model. What we show is that typically the former is expected to be less than the latter. ${ }^{11}$ However, we can establish an upper bound on the difference between the two measures empirically based on the findings of previous studies. Cukierman and Wachtel (1979) found that $\sigma^{2} / \tau_{z}^{2}$, the ratio of the variance of the general price level to the variance of relative prices, was always less than unity during the sample period 1948-74 and, except for five years, it was less than 0.15 . Thus, we see that a value of $\sigma^{2} / \tau_{z}^{2}<1$ would imply $\overline{\mathrm{Var}}+$ Disag to be at least $0.75 \sigma^{2}$, and larger than $0.98 \sigma^{2}$ if $\sigma^{2} / \tau_{z}^{2}<0.15$. We also computed $\sigma^{2} / \tau_{z}^{2}$ with the annual PPI data during 1948-1989 from Ball and Mankiw (1995). These authors calculated PPI inflation and weighted standard deviation of relative price change for each year. We calculated $\sigma$ as the standard error from an AR(1) regression of PPI inflation. We found that during this period $\sigma^{2} / \tau_{z}^{2}$ is equal to 0.42 on the average, which implies that $\overline{\mathrm{Var}}+$ Disag $=0.91 \sigma^{2}$.

Figure 1 shows the extent of underestimation of $\overline{\operatorname{Var}}+$ Disag as a function of $\sigma^{2} / \tau_{z}^{2}$. As expected, the smaller this ratio, the closer will be $\overline{\operatorname{Var}}+$ Disag to $\sigma^{2}$. For example, if $\sigma^{2} / \tau_{z}^{2}$ is less than $0.1, \overline{\text { Var }}+$ Disag $>0.99 \sigma^{2}$. Intuitively, the higher the variance of individual specific shocks relative to that of the general price level, the lower is the value of $p_{t}(z)$ in predicting $p_{t}$. This is because it is harder for individuals to extract information about $p_{t}$ from the strong background noise of individual specific shock $z$. Equation (2-2) shows that, under this situation, individuals will rely more heavily on

\footnotetext{
${ }^{11}$ It is interesting to note that the so-called fan charts depicting multi-period forecast uncertainty as generated by Bank of England and Riksbank are very similar in spirit to the variance of the aggregate density from SPF. Starting from a base line model predictions that all share, bank economists and forecasting experts subjectively generate these charts incorporating their individual beliefs and specialized knowledge.

In a recent paper, Cogley et al. (2003) show that the predictive intervals estimated from a Bayesian VAR that incorporates diverse statistical sources of uncertainty including model uncertainty, policy drift, structural shifts, and other shocks are more diffuse that the Bank of England's fan charts. This result is consistent with our equation (2-6). See Garratt et al. (2003) for a similar forecasting model generating uncertainty.
} 
$\bar{p}_{t}$ to form their forecasts. If $\theta_{z}=1$ in $(2-2), p_{t}(z)$ provides no information about $p_{t}$, and individual forecasters will just report $\bar{p}_{t}$ as their point forecasts. Then $\overline{V a r}+$ Disag will be exactly equal to $\sigma^{2}$.

Under the assumption that the variances of individual specific shocks are the same, i.e., $\tau_{1}^{2}=\tau_{2}^{2}=\cdots=\tau_{N}^{2}=\tau^{2}$, we can establish the lower bound of $\overline{V a r}+$ Disag in another way. First note that if the variances of individual specific shock are identical, (2-3), (2-4) and (2-6) can be simplified as $\overline{V a r}=\theta \sigma^{2}$, Disag $=(1-\theta)^{2} \tau^{2}, \overline{V a r}+$ Disag $=\left(1-(1-\theta)^{2}\right) \sigma^{2}$, where $\theta=\tau^{2} /\left(\tau^{2}+\sigma^{2}\right)$. After litter algebra, we can get

$$
\overline{V a r}+\operatorname{Disag}=\left(1-(\text { Disag } / \overline{\text { Var }})^{2}\right) \sigma^{2}
$$

In section 5, we have estimated the average Disag $/ \overline{V a r}$ to be 0.27 for the SPF data during the sample period 1968Q4-2003Q4. Substituting this number into (2-7), we get $\overline{V a r}+$ Disag to be approximately $0.92 \sigma^{2}$. From all these analysis using both time series and survey data evidence, we may safely conclude that $\overline{V a r}+$ Disag is usually between $90 \%$ and $100 \%$ of the time series measures of forecast uncertainty. Therefore, when comparing survey and time series measures of forecast uncertainty, we should include both the average individual forecast uncertainty and forecast disagreement as the measure of collective forecast uncertainty for the economy. This amounts to the use of variance of the aggregate forecast density as advocated by Diebold et al. (1999) and Wallis (2004).

The model we have just discussed mimics the Survey of Professional Forecasters (SPF) data set. The survey is mailed four times a year, on the day after the first (preliminary) release of the NIPA data for previous quarter. Forecasters are asked to return the survey before the middle of each forecasting quarter. Therefore, even though forecasters share common information about previous quarters, they also have some private information gathered during the forecasting quarter. During the 45 - 60 days from the end of previous quarter to when they actually report their forecasts, respondents can obtain partial 
information about current quarter from many objective sources. It may also be their individual experiences in specific markets and their beliefs regarding the effects of current "news" on future inflation. ${ }^{12}$ Thus the data generating process of SPF is consistent with the simple model we have suggested. This framework provides a guide to compare survey measures from SPF data and time series measures of forecast uncertainty.

We have assumed that the specification of the time series model is correct, and that forecast failure does not happen due to structural breaks and policy changes. In reality, however, time series data generating processes are subject to breaks and model uncertainty. These possibilities will complicate the simple correspondence between survey and time series measures of forecast uncertainty. However, our analysis suggests that individually neither the average variance of the individual forecast densities nor the variance of the point forecasts, but their sum, should be used to approximate the forecast uncertainty generated from a correctly specified time series model.

\section{Econometric framework}

In previous section, we showed that the forecast uncertainty of an outside observer might be approximated by the sum of average forecast error variance and forecast disagreement, $\overline{V a r}+$ Disag. In this section, we outline how to calculate $\overline{V a r}+$ Disag from SPF data. This issue is not as simple as one might think since the survey respondents are often asked to assign a probability of outcome to various intervals rather than to produce a continuous density function. Thus, how to extract the correct information from the density forecasts data is a problem. The standard approach to calculate the mean and variance from individual density forecasts is as follows (see, for instance, Lahiri and Teigland (1987) and Lahiri, Teigland and Zaporowski (1988)).

$$
E(F)=\sum_{j=1}^{J} F_{j} \operatorname{Pr}(j) \text { and } \operatorname{Var}(F)=\sum_{j=1}^{J}\left[F_{j}-E(F)\right]^{2} \operatorname{Pr}(j)
$$

\footnotetext{
${ }^{12}$ In addition to informational difference, use of different forecasting models, different beliefs, and subjective factors may be other reasons for the diversity of forecasts, see Kurz and Motolese (2001). Bomberger (1996) has emphasized the role of different models in generating disagreement.
} 
where $F_{j}$ and $\operatorname{Pr}(\mathrm{j})$ are the midpoint and probability of interval $\mathrm{j}$, respectively. The lowest and highest intervals, which are open, are typically taken to be closed intervals of the same width as the interior intervals.

This approach implicitly assumes that all probability mass is concentrated at the interval midpoints. However, it will lead to the so-called "grouping data error". The standard approach to correcting for grouping data error is "Sheppard's correction" (Stuart and Ord (1994)), which gives the corrected mean the same as the uncorrected mean, but the corrected variance as the uncorrected variance minus $1 / 12$ of the squared bin width. Though popular, there are problems with the Sheppard's corrections when applied to SPF data. ${ }^{13}$ An alternative proposed by Giordani and Soderlind (2003) is to fit normal distributions to each histogram, and the mean and variance are estimated by minimizing the sum of the squared difference between the survey probabilities and the probabilities for the same intervals implied by the normal distribution. We will follow their approach in this paper ${ }^{14}$.

To obtain an appropriate measure of inflation forecast uncertainty, we need to correct for not only the grouping error, but also the errors due to systematic individual biases in forecast densities. In recent years, the individual heterogeneity in economic forecasts has been increasingly emphasized. For example, Lahiri and Ivanova (1998) and Souleles (2004) use data from the Michigan Index of Consumer Sentiment, and document differences across demographic and other groups in their inflation expectations. Mankiw, Reis and Wolfers (2003) also document substantial disagreement among economic agents about expected future inflation using survey data from different sources. Mankiw and Reis (2002) propose a "sticky-information" model to explain the variation of disagreement over time. A similar model by Carroll (2003) emphasizes the differential effect of macroeconomic news on household expectations. Disagreement results from the

\footnotetext{
${ }^{13}$ For example, in the first quarter of 1985 , many forecasters put most of the probability mass in the open lower interval.

${ }^{14}$ We are grateful to Paolo Giordani and Paul Söderlind for kindly providing their programs.
} 
differences across demographic groups in their propensity to pay attention to news reports.

Although the literature has focused mostly on the heterogeneity in point forecasts, some authors have raised the issue of heterogeneity in forecast uncertainty also. For example, Davies and Lahiri $(1995,1999)$ decompose the variance of forecast errors into variances of individual-specific forecast errors and aggregate shocks. They found significant heterogeneity in the former. Rich and Tracy (2003) also find evidence of statistically significant forecaster fixed effects in SPF density forecasts data. They take this as evidence that forecasters who have access to superior information or possess a superior ability to process information are more confident in their point forecasts. Ericsson (2003) studies the determinants of forecast uncertainty systematically. He points out that forecast uncertainty depends upon the variable being forecast, the type of model used for forecasting, the economic process actually determining the variable being forecast, the information available and the forecast horizon. If different forecasters have different information sets and use different forecast models, the anticipated forecast uncertainties will be different across forecasters even if agents are forecasting the same variable at the same forecast horizon. In the following part of this section, we extend the framework of Davies and Lahiri $(1995,1999)$ to illustrate how to correct for heterogeneity in forecasts.

Let $t$ denotes the target period of forecast, $h$ denotes the forecast horizon, or the time left between the time the forecast was made and $t$, and $i$ denotes the forecaster. Let $A_{t}$ be the realized value, or the actual, of the forecasted variable, and let $A_{t h}$ be the latest realization known to forecasters at the time of forecast. Let $\gamma_{t h}$ denotes the full-information (this is equivalent to the past history of the economy in the previous section) expected change in the actual over the forecast period. Let $F_{i t h}$ denotes the point forecast made by forecaster $i$ at time $t$ - $h$ about the inflation rate in period $t$. Because we can expect errors in information collection, judgment, calculation, transcription, etc. as well as private information, not all forecasts will be identical. Let us call these differences as "idiosyncratic" error and let $\mu_{i t h}$ be individual $i$ 's idiosyncratic error associated with his 
forecast for target $t$ made at horizon $h$. Finally, let $\phi_{i}$ be forecaster $i$ 's overall average bias. Using these notations, the individual point forecast can be expressed as:

$$
F_{i t h}=A_{t h}+\gamma_{t h}+\mu_{i t h}+\phi_{i}
$$

Note that the presence of systematic bias $\phi_{i}$ does not necessarily imply that forecasters are irrational. The reasons of systematic forecast bias may include asymmetric loss function used by forecasters (see Zellner (1986), and Christofferson and Diebold (1997)), or the propensity of forecasters to achieve publicity for extreme opinions (Laster, Bennett and Geoum (1999)).

Using (3-1), the disagreement among forecasters at time $t-h$ is then

$$
\frac{1}{N} \sum_{i=1}^{N}\left(F_{i t h}-F_{t h}\right)^{2}=\frac{1}{N} \sum_{i=1}^{N}\left(\phi_{i}-\phi .+\mu_{i t h}-\mu_{t h}\right)^{2}=\sigma_{\phi}^{2}+\sigma_{\mu_{t h}}^{2}
$$

In (3-2), $\sigma_{\phi}^{2}$ reflects the dispersion of systematic forecast biases across forecasters and is unrelated to the forecast target and forecast horizon. So it does not reflect forecasters' difference in views about how price level will change in $h$ period ahead. Only $\sigma_{\mu_{t h}}^{2}$ should be included in the calculation of forecast disagreement for it reflects forecasters' disagreement because of differential information sets (or different forecasting models).

Assuming rationality, and in the absence of aggregate shocks, the actual at the end of period $t$ will be the actual at the end of period $t-h\left(A_{t h}\right)$ plus the full information anticipated change in the actual from the end of period $t$ - $h$ to the end of period $t\left(\gamma_{t h}\right)$. Let the cumulative aggregate shocks occurring from the end of period $t-h$ to the end of period $t$ be represented by $\lambda_{t h}$. By definition, $\lambda_{t h}$ is the component of the actual that is not anticipated by any forecaster. Then, the actual inflation of period $t$ can be expressed as 


$$
A_{t}=A_{t h}+\gamma_{t h}+\lambda_{t h}
$$

Note that the aggregate shocks from the end of $t-h$ to the end of $t\left(\lambda_{t h}\right)$ are comprised of two components: changes in the actual that occurred but were not anticipated, and changes in the actual that were anticipated but did not occur.

Subtracting (3-1) from (3-3) yields an expression for forecast error where forecasts differ from actuals due to individual biases, cumulative aggregate shocks, and idiosyncratic errors.

$$
e_{i t h}=A_{t}-F_{i t h}=\phi_{i}+\lambda_{t h}+\mu_{i t h}
$$

Then the individual forecast error variance $\left(V_{i t h}\right)$ can be expressed as

$$
V_{i t h}=\operatorname{Var}_{i}\left(e_{i t h}\right)=\operatorname{Var}_{i}\left(\phi_{i}+\lambda_{t h}+\mu_{i t h}\right)=\operatorname{Var}_{i}\left(\lambda_{t h}\right)+\operatorname{Var}_{i}\left(\mu_{i t h}\right)
$$

The first term $\operatorname{Var}_{i}\left(\lambda_{t h}\right)$ measures the perceived uncertainty of aggregate shocks. We allow them to be different across individuals. This is consistent with the model in previous section in which individuals have different probability forecasts for the aggregate price level due to heterogeneity in information and other reasons. As for the variance of idiosyncratic forecast errors, we assume it is constant over $t$ and $h$ but varies across $i$. Or more specifically, we assume $\mu_{i t h} \sim N\left(0, \sigma_{i}^{2}\right)$. This term captures the fixed effects in the individual forecast error variance. From (3-5), only $\operatorname{Var}_{i}\left(\lambda_{t h}\right)$ should be included in the measure of inflation forecast uncertainty. $\sigma_{i}^{2}$ is unrelated to the target itself and should be excluded from the aggregate measure of inflation uncertainty in order to control for compositional effects in the variance, see Rich and Tracy (2003).

As showed in the previous section, the average individual forecast error variance should be included in the measure of aggregate inflation forecast uncertainty. Based on (3-5), it can be calculated as 


$$
\frac{1}{N} \sum_{i} V_{i t h}=\frac{1}{N} \sum_{i} \operatorname{Var}_{i}\left(\lambda_{t h}\right)+\frac{1}{N} \sum_{i} \sigma_{i}^{2}
$$

As discussed above, an accurate measure of uncertainty should include only $\sigma_{\lambda_{t h}}^{2}=\frac{1}{N} \sum_{i} \operatorname{Var}_{i}\left(\lambda_{t h}\right)$. Thus the measure of forecast uncertainty calculated as $\overline{\operatorname{Var}}+$ Disag is

$$
U_{t h}=\sigma_{\lambda_{t h}}^{2}+\sigma_{\mu_{t h}}^{2}
$$

\section{Data}

We apply the model developed in previous section to SPF (Survey of Professional Forecasters) data set. As noted before, SPF was started in the fourth quarter of 1968 by American Statistical Association and National Bureau of Economic Research and taken

over by the Federal Reserve Bank of Philadelphia in June 1990. The respondents are professional forecasters from academia, government, and business. The survey is mailed four times a year, the day after the first release of the NIPA (National Income and Product Accounts) data for the preceding quarter. Most of the questions ask for the point forecasts on a large number of variables for different forecast horizons. A unique feature of SPF data set is that forecasters are also asked to provide density forecasts for aggregate output and inflation. In this study, we will focus on the latter. Before we use this data, we need first to consider several issues, including:

(1) The number of respondents changes over time. It was about 60 at first and decreased in mid 1970s and mid 1980s. In recent years, the number of forecasters was around 30 . So, we have an incomplete panel data.

(2) The number of intervals or bins and their length has changed over time. During 1968Q4-1981Q2 there were 15 intervals, during 1981Q3-1991Q4 there were 6 intervals, and from 1992Q1 onwards there are 10 intervals. The length of each 
interval was 1 percentage point prior to 1981Q3, then 2 percentage points from 1981Q3 to 1991Q4, and subsequently 1 percentage point again.

(3) The definition of inflation in the survey has changed over time. It was defined as annual growth rate in GNP implicit price deflator (IPD) from 1968Q4 to1991Q4. From 1992Q1 to 1995Q4, it was defined as annual growth rate in GDP IPD. Presently it was defined as annual growth rate of chain-type GDP price index.

(4) Following NIPA, the base year for price index has changed over our sample period. It was 1958 during 1968Q4 - 1975Q4, 1972 during 1976Q1 - 1985Q4, 1982 during 1986Q1 - 1991Q4, 1987 during 1992Q1 - 1995Q4, 1992 during 1996Q1 - 1999Q3, 1996 during 1999Q4 - 2003Q4, and finally 2000 from 2004Q1 onwards.

(5) The forecast horizon in SPF has changed over time. Prior to 1981Q3, the SPF asked about the annual growth rate of IPD only in the current year. Subsequently it asked the annual growth rate of IPD in both the current and following year. However, there are some exceptions. In certain surveys before 1981Q3, the density forecasts referred to the annual growth rate of IPD in the following year, rather than the current year ${ }^{15}$. Moreover, the Federal Reserve Bank of Philadelphia is uncertain about the target years in the surveys of 1985Q1 and 1986Q1. Therefore, even though for most target years, we have eight forecasts with horizons varying from approximately ${ }^{1 / 2}$ to $7^{1 / 2}$ quarters ${ }^{16}$, for some target years, the number of forecasts is less than eight.

Problem (2) to (4) can be handled by using appropriate actual values and intervals although they may cause the estimation procedure a little more complicated. Following Zarnowitz and Lambros (1987), we focus on the density forecasts for the change from year $t-1$ to year $t$ that were issued in the four consecutive surveys from the last quarter of year $t$-1 through the third quarter of year $t$. The actual horizons for these four forecasts are approximately $4^{1} / 2,3^{1} / 2,2^{1} / 2$, and $1^{1} / 2$ quarters but we shall refer to them simply as horizons $4, \ldots, 1$. Problem (1) and (5) implies that we will have a lot missing values.

\footnotetext{
15 The surveys for which this is true are 1968Q4, 1969Q4, 1970Q4, 1971Q4, 1972Q3 and Q4, 1973Q4, 1975Q4, 1976Q4, 1977Q4, 1978Q4, and 1979Q2 - Q4.

${ }^{16}$ Forecasts are made around the middle of each quarter.
} 
After eliminating observations with missing data, we obtained a total of 4942 observations over the sample period from 1968Q4 to 2004Q3. For purpose of estimation, we need to eliminate observations for infrequent respondents. Following Zarnowitz and Lambros (1987), we focus on the "regular" respondents who participated in at least 12 surveys during the sample period. This subsample has 4215 observations in total.

To estimate the model, we also need data on the actual, or realized values of IPD inflation ( $A_{t}$ as in previous section). Since the NIPA data often goes through serious revisions, we need to select the appropriate data for the actual. Obviously, the most recent revision is not a good choice because forecasters cannot forecast revisions occurring many years later. Especially, the benchmark revision often involved adjustment of definitions and classifications, which is beyond the expectation of forecasters. Thus, we choose the first July revisions of the annual IPD data to compute $A_{t}$. For example, we compute inflation rate from 1968 to 1969 as

$$
A_{t}=100 *\left(\frac{I P D_{1969,1}^{J}+I P D_{1969,2}^{J}+I P D_{1969,3}^{J}+I P D_{1969,4}^{J}}{I P D_{1968,1}^{J}+I P D_{1968,2}^{J}+I P D_{1968,3}^{J}+I P D_{1968,4}^{J}}-1\right)
$$

where $I P D_{1969, q}^{J}$ is the IPD level in the $\mathrm{q}^{\text {th }}$ quarter of year 1969 released in July 1970 and $I P D_{1968, q}^{J}$ is the IPD level in the $\mathrm{q}^{\text {th }}$ quarter of year 1968 released in July 1969. These are the real-time data available from the Federal Reserve Bank of Philadelphia. See section 6 for more detailed description of this data set.

\section{Estimation}

In this section, we describe how to extract inflation forecast uncertainty as defined in section 3 from SPF data set. By (3-4), forecast error can be decomposed into three parts:

$$
e_{i t h}=A_{t}-F_{i t h}=\lambda_{t h}+\phi_{i}+\mu_{i t h}
$$


Note that, $\mu_{i t h}$ is uncorrelated over $i, t, h$ and $\lambda_{t h}$ is uncorrelated over $t$. In addition, they both have zero mean and are uncorrelated with each other under the assumption of rational expectation. Following Davies and Lahiri (1999), an estimate of systematic forecast bias can then be derived as follows:

$$
\hat{\phi}_{i}=\frac{1}{T H} \sum_{t} \sum_{h}\left(A_{t}-F_{i t h}\right)
$$

The mean bias across all forecasters is then

$$
\hat{\phi}=\frac{1}{N} \sum_{i} \hat{\phi}_{i}
$$

and the variance of individual bias across forecasters is

$$
\hat{\sigma}_{\phi}^{2}=\frac{1}{N-1} \sum_{i}\left(\hat{\phi}_{i}-\hat{\phi}\right)^{2}
$$

Note that, the composition of forecasters varies over both $t$ and $h$, which implies that $\sigma_{\phi}^{2}$ also changes over $t$ and $h$.

Using (3-2), we can obtain estimates of inflation forecast disagreement as

$$
\hat{\sigma}_{\mu_{t h}}^{2}=\frac{1}{N} \sum_{i=1}^{N}\left(F_{i t h}-F_{. t h}\right)^{2}-\hat{\sigma}_{\phi}^{2}
$$

Note that (5-4) is computed over the subsample of "regular" respondents. So, we implicitly assume that including infrequent respondents will not change the estimate of forecast disagreement appreciably. 
Next we consider the estimation of the average individual forecast error variance as defined in section 3. From (3-5), we have

$$
V_{i t h}=\operatorname{Var}_{i}\left(\lambda_{t h}\right)+\sigma_{i}^{2}
$$

As argued in previous section, $\sigma_{i}^{2}$ should not be included in the aggregate measure of forecast uncertainty. The distribution of forecasters over time is not random. Some forecasters participated only in the early period of the survey, others may participate only in the later period. Following Rich and Tracy (2003), we regress the variances of individual densities on a set of year dummy variables and a set of individual dummy variables for each forecast horizon. The estimated respondent fixed effects reflect the extent to which a particular respondent's inflation uncertainty systematically differs from the average adjusting for the years that the respondent participated in the survey. By subtracting out these fixed-effect estimates from the respondent's inflation uncertainty estimates, we can control for the changes in the composition of the survey. Then by applying (3-6), we obtain the average individual forecast error variance corrected for the “composition" effect, i.e. $\hat{\sigma}_{\lambda_{h l}}^{2}$.

Given the estimates of forecast disagreement and average individual forecast error variance, we could compute the inflation forecast uncertainty based on (3-7) as

$$
\hat{U}_{t h}=\hat{\sigma}_{\lambda_{t h}}^{2}+\hat{\sigma}_{\mu_{t h}}^{2}
$$

However, when plotting inflation forecast uncertainty and its two components with different horizons pooled together, one more adjustment seems reasonable. There is a possibility that the same shocks occurring at two different horizons relative to the same target will have different effects on forecaster's confidence about his forecast. Forecasters may be more uncertain about the effect of a shock when the horizon in long. This type of "horizon effects" should be removed when we want to examine how forecast uncertainty 
varies over time continuously over quarters. To remove the horizon effects, we regressed $\operatorname{Var}_{i}\left(\lambda_{t h}\right)$ on horizon dummies. More specifically,

$$
\operatorname{Var}_{i}\left(\lambda_{t h}\right)=\alpha_{i}+D_{1} \delta_{i 1}+D_{2} \delta_{i 2}+D_{3} \delta_{i 3}+v_{i t h}
$$

where $D_{h}=\left\{\begin{array}{l}1 \text { if observation is for horizon } h, h=1,2,3 \\ 0 \text { otherwise }\end{array}\right.$

Note that $\delta_{i h}$ measures the difference between forecast error variance with horizon of four quarters and those with others. That implies forecasts with horizon of four quarters are the benchmark for comparison. We converted forecasts with horizons less than four quarters to forecasts with 4-quarter horizon. Since we are only interested in the average horizon effects, we formulate (5-7) as a random coefficients model. Specifically, we assume that

$$
\left(\alpha_{i}, \delta_{i 2}, \delta_{i 3}, \delta_{i 4}\right)=\left(\alpha, \delta_{2}, \delta_{3}, \delta_{4}\right)+v_{i} \text { with } E\left(v_{i}\right)=0 \quad E\left(v_{i} v_{i}^{\prime}\right)=\Gamma
$$

Model (5-7) (5-8) can be estimated ${ }^{17}$ using the method formulated in Greene (2000). Then the estimated average 4-quarter equivalent individual forecast error variance and inflation forecast uncertainty are $\hat{\sigma}_{\lambda_{t h}}^{2}-\hat{\delta}_{h}$ and $\hat{\sigma}_{\lambda_{t h}}^{2}-\hat{\delta}_{h}+\hat{\sigma}_{\mu_{t h}}^{2}$ respectively. ${ }^{18}$

Figures $2 \mathrm{a}$ and $2 \mathrm{~b}$ present the estimated uncertainty $\left(\hat{U}_{t h}-\hat{\delta}_{h}\right)$ and its two components, the average variance $\left(\hat{\sigma}_{\lambda_{t h}}^{2}-\hat{\delta}_{h}\right)$ and the disagreement $\left(\hat{\sigma}_{\mu_{t h}}^{2}\right)$, from 1968Q4 to 2003Q4. ${ }^{19}$

First, we see that the inflation forecast uncertainty as measured by $\hat{U}_{t h}-\hat{\delta}_{h}$ was low

\footnotetext{
${ }^{17}$ (5-7) and (5-8) are estimated for forecasters who participated in the survey for 28 or more times to ensure that each forecaster report at least one observation for each forecast horizon.

${ }^{18}$ We should point out that these adjustments for horizons were done solely for presenting the uncertainty as a quarterly series in Figures $2 \mathrm{a}$ and $2 \mathrm{~b}$. All other analysis was conducted with horizon effects left in.

${ }^{19}$ It is necessary to explain the meaning of numbers in Figure 2a-2b. Taking uncertainty in 1972 as an example, it is about 1, which means that the standard deviation is also 1 . So, a $90 \%$ confidence band constructed from a normal distribution would have been $\pm 1.6 \%$ around the point forecast in 1972. It would be $[2.4 \%, 5.6 \%]$ if the point forecast is $4 \%$.
} 
before 1973 and after 1992. This is consistent with previous studies. A similar pattern persists for its two components also. This roughly confirms Friedman's (1977) conjecture that greater inflation uncertainty is associated with higher levels of inflation. Second, the forecast disagreement on the average over the whole sample period is lower $(0.38)$ than the average of individual forecast uncertainty $(0.70)$ over the sample period. This is consistent with the empirical findings in previous studies such as Zarnowitz and Lambros (1987). Third, forecast disagreement increased significantly in mid 1970s and early 1980s. In mid 1970s, the US economy was hit by the first oil shock. Such an event raises people's uncertainty about future change in the inflation regime. But it had interestingly only a slight effect on the average variance of inflation, $\hat{\sigma}_{\lambda_{h l}}^{2}-\hat{\delta}_{h}$. The late 1970s and early 1980s witnessed similar episodes when the economy is hit by the second oil shock and a sudden change in monetary policy regime from the interest rate targeting to the targeting of money supply. ${ }^{20}$ Fourth, the sample variance of forecast disagreement is 0.19 over the sample period while that for the average individual forecast uncertainty is 0.11 . This is consistent with Lahiri et al. (1988)'s finding that forecast disagreement tend to be more volatile than the average individual forecast uncertainty. Fifth, the correlation coefficient of the overall measure of uncertainty $\left(\hat{U}_{t h}-\hat{\delta}_{h}\right)$ with average variance $\left(\hat{\sigma}_{\lambda_{t h}}^{2}-\hat{\delta}_{h}\right)$ and forecast disagreement $\left(\hat{\sigma}_{\mu_{t h}}^{2}\right)$ are 0.72 and 0.85 respectively. This result implies that forecast disagreement is a good proxy for uncertainty. Almost all studies in this area have reached this conclusion. Finally, note from table 1 that there are significant horizon effects. This, of course, is expected.

\section{GARCH model of uncertainty}

In section 2, we argued that the sum of the forecast disagreement and the average individual forecast error variance approximates the time series measure of uncertainty fairly well. In this section, we test how well this argument is true by comparing these two

\footnotetext{
${ }^{20}$ Evans and Wachtel (1993) find that forecast disagreement is more closely associated with regime uncertainty than the uncertainty with a given inflation structure. Since everyone knew about the change in monetary policy, the abrupt shift in disagreement in the early 80 s had to be due to different beliefs and models rather than due to different information sets, see Fulford (2002) and Kurz (2002).
} 
measures empirically. The most popular time series models for estimating forecast uncertainty are $\mathrm{ARCH}$ and its various extensions. In these models, the forecast uncertainty is measured as the time varying conditional variance of innovations. ${ }^{21}$

Following Engle and Kraft (1983), we model quarterly inflation $\pi_{t}$ as an AR(4) process

$$
\pi_{t}=\beta_{0}+\beta_{1} \pi_{t-1}+\beta_{2} \pi_{t-2}+\beta_{3} \pi_{t-3}+\beta_{4} \pi_{t-4}+\varepsilon_{t}
$$

To test for the presence of conditional heteroscedasticity in the form of ARCH/GARCH process, we estimated (6-1) by OLS on quarterly inflation data from 1955Q2 to 2004Q2 released in 2004Q3. The squared residuals are then regressed on it's own lags up to 20 . The $\chi^{2}$ test statistic was significant at the significance level of $5 \%$, suggesting that $\mathrm{ARCH} / \mathrm{GARCH}$ effect is presented. ${ }^{22}$

To capture the ARCH/GARCH effect, we tried three formulations for the conditional variance of $\varepsilon_{t}$ : the popular GARCH(1,1) model in which the conditional variance of inflation is formulated as

\section{$\underline{\operatorname{GARCH}(1,1):}$}

$$
h_{t}=E\left(\varepsilon_{t}^{2} \mid \psi_{t-1}\right)=\alpha_{0}+\alpha_{1} \varepsilon_{t-1}^{2}+\alpha_{2} h_{t-1}
$$

where $\alpha_{0}>0, \alpha_{1} \geq 0, \alpha_{2} \geq 0, \alpha_{1}+\alpha_{2}<1^{23}$ and $\psi_{t-1}=\left\{\pi_{t-1}, h_{t-1}, \varepsilon_{t-1} \ldots\right\}$ is the information set at date $t-1$.

\section{$\underline{\operatorname{ARCH}(4):}$}

$$
h_{t}=E\left(\varepsilon_{t}^{2} \mid \psi_{t-1}\right)=\alpha_{0}+\alpha_{1} \varepsilon_{t-1}^{2}+\alpha_{2} \varepsilon_{t-2}^{2}+\alpha_{3} \varepsilon_{t-3}^{2}+\alpha_{4} \varepsilon_{t-4}^{2}
$$

\footnotetext{
${ }^{21}$ See Engle (1982, 1983), Bollerslev(1986), Nelson (1991), Glosten, Jagannathan and Runkle(1993) and surveys by Bollerslev, Chou and Kroner(1992), Bera and Higgins (1993).

${ }^{22}$ The value of the test statistic $T R^{2}$ was equal to 36.81 . The critical value for $\chi^{2}$ test with 20 degree of freedom is 31.4 at significance level of $5 \%$.

${ }^{23}$ These conditions are sufficient but not necessary to ensure stationarity and nonnegativity of $h_{t}$.
} 
where $\alpha_{0}>0, \alpha_{1} \geq 0, \alpha_{2} \geq 0, \sum_{i=1}^{4} \alpha_{i}<1$.

\section{GJR-GARCH(1,1):}

$$
h_{t}=E\left(\varepsilon_{t}^{2} \mid \psi_{t-1}\right)=\alpha_{0}+\alpha_{1} \varepsilon_{t-1}^{2}+\alpha_{2} h_{t-1}+\alpha_{3} D_{t-1} \varepsilon_{t-1}^{2}
$$

where $\alpha_{0}>0, \alpha_{1} \geq 0, \alpha_{2} \geq 0, \alpha_{1}+\alpha_{2}+0.5 \alpha_{3}<1$ and

$$
D_{t}= \begin{cases}1 & \text { if } \varepsilon_{t}<0 \\ 0 & \text { otherwise }\end{cases}
$$

Tables 2-4 show the estimates of the three models over the same sample as above. Values of t-statistics, log likelihood, AIC and SC reveal that GJR-GARCH(1,1) model provides the best fit among the three models. This result is meaningful since it is well known that an unpredicted fall in inflation produces less uncertainty than an unpredicted rise in inflation. (Giordani and Soderlind (2003)). One explanation may be that during a period of unexpected high inflation, people are uncertain about whether or not the monetary authorities will adopt a disinflationary policy at the potential cost of higher unemployment or lower growth rate of output. However, if there is unexpected low inflation, people believe that the monetary authorities will seek to maintain the low inflation, so inflation forecast uncertainty would be low. Actually, Ball (1992) use this argument to explain why higher inflation leads to higher inflation uncertainty.

To make the time series results comparable to the survey measure, we estimated the model with real-time macro data available from the Federal Reserve Bank of Philadelphia. ${ }^{24}$ This data set includes information as they existed in the middle of each quarter from November 1965 to the present. For each vintage date, the observations are identical to those one would have observed at that time. To estimate our models, we

\footnotetext{
${ }^{24}$ A description of this data set can be found in Croushore and Stark(2001).
} 
make use of only the data for Output Price Index. ${ }^{25}$ (It was first GNP IPD, then GDP IPD and finally Chain-weighted price index for real GDP since 1996, see section 4 for detail discussion). The quarterly inflation rate is defined as log difference of quarterly price index. Specifically,

$$
\pi_{t}=100 *\left(\ln \left(p_{t}\right)-\ln \left(p_{t-1}\right)\right)
$$

where $p_{t}$ denote the price level at date $t$.

The estimation and forecast procedure is as follows. First, the above models are estimated using the quarterly inflation data available at a particular point of time starting from 1955Q1 and ending at the last quarter before the forecasting date. This construction is intended to reproduce the information sets of forecasters in real time. Then the estimated model is used to forecast the inflation forecast uncertainty. Since the survey measure reports uncertainty associated with the forecast of annual inflation rate in the target year made in different quarters before the end of that year, we cannot just compare the conditional variance of quarterly inflation forecasts with the survey measure directly. Previous studies have not been sufficiently clear about this important issue. Based on the models for quarterly inflation, however, we could derive a measure of forecast uncertainty comparable to the survey measure. For that purpose, we should first make some changes to the previous notations.

Let $\pi_{t}$ denotes annual inflation rate for year $t, \pi_{t, i}$ denotes quarterly inflation rate in the $i^{t h}$ quarter of year $t$, and $p_{t, i}$ denotes the price index for the $i^{t h}$ quarter of year $t$. Consider the

\footnotetext{
${ }^{25}$ The data is seasonally adjusted. For the vintage of 1996Q1, the observation for 1995Q4 is missing because of a delay in the release of statistical data caused by the federal government shutdown. For most vintages, the data start from 1947Q1. For some vintages, data may start at a different date. So, the number of observations for estimation varies across vintages not only because more observations are included over time, but also because the changes of starting date. But this only occurs for 1992Q1-1992Q4, 1999Q42000Q1 (starting date is 1959Q1) and 1996Q1-1997Q2 (starting date is 1959Q3) with a total of 12 among 141 vintages.
} 
forecast for annual inflation rate in year $t$ made in the first quarter of that year. ${ }^{26}$ By definition, the annual inflation rate in year $t$ can be expressed as the sum of quarterly inflation rate in each quarter of that year.

$$
\begin{aligned}
& \pi_{t}=100 *\left(\ln \left(p_{t, 4}\right)-\ln \left(p_{t-1,4}\right)\right)=100 *\left(\ln \left(p_{t, 4}\right)-\ln \left(p_{t, 3}\right)+\ln \left(p_{t, 3}\right)-\ln \left(p_{t, 2}\right)\right. \\
& \left.+\ln \left(p_{t, 2}\right)-\ln \left(p_{t, 1}\right)+\ln \left(p_{t, 1}\right)-\ln \left(p_{t-1,4}\right)\right)=\pi_{t, 4}+\pi_{t, 3}+\pi_{t, 2}+\pi_{t, 1}
\end{aligned}
$$

The forecast for $\pi_{t}$ in the first quarter of that year is as follows:

$$
\begin{aligned}
& \pi_{t}^{f}=100 *\left(\ln \left(p_{t, 4}^{f}\right)-\ln \left(p_{t-1,4}\right)\right)=100 *\left(\ln \left(p_{t, 4}^{f}\right)-\ln \left(p_{t, 3}^{f}\right)+\ln \left(p_{t, 3}^{f}\right)-\ln \left(p_{t, 2}^{f}\right)\right. \\
& \left.+\ln \left(p_{t, 2}^{f}\right)-\ln \left(p_{t, 1}^{f}\right)+\ln \left(p_{t, 1}^{f}\right)-\ln \left(p_{t-1,4}\right)\right)=\pi_{t, 4}^{f}+\pi_{t, 3}^{f}+\pi_{t, 2}^{f}+\pi_{t, 1}^{f}
\end{aligned}
$$

where $X^{f}$ denotes the forecast for the variable $X$ made in the first quarter ${ }^{27}$ of the year considered. So, the forecast horizon varies for predicting different quarterly inflation rates. For example, the forecast horizon is $1 / 2$ quarter for forecasting quarterly inflation in the first quarter but $3^{1} / 2$ quarters for forecasting quarterly inflation in the fourth quarter.

The error with annual inflation forecast made in the first quarter of year $t$ is the difference between $\pi_{t}$ and $\pi_{t}^{f}$.

$$
e_{t}=\pi_{t}-\pi_{t}^{f}=\left(\pi_{t, 4}+\pi_{t, 3}+\pi_{t, 2}+\pi_{t, 1}\right)-\left(\pi_{t, 4}^{f}+\pi_{t, 3}^{f}+\pi_{t, 2}^{f}+\pi_{t, 1}^{f}\right)=e_{t, 4}+e_{t, 3}+e_{t, 2}+e_{t, 1}
$$

where $e_{t, i}$ is the error of forecasting the $i^{\text {th }}$ quarterly inflation of year $t$ made in the first quarter of the same year. As before, the quarterly inflation is modeled as AR(4). So, the forecast for quarterly inflation rate of the fourth quarter of year $t$ is

$$
\pi_{t, 4}=\beta_{0}+\beta_{1} \pi_{t, 3}+\beta_{2} \pi_{t, 2}+\beta_{3} \pi_{t, 1}+\beta_{4} \pi_{t-1,4}+\varepsilon_{t, 4}
$$

\footnotetext{
${ }^{26}$ This forecast actually has a forecast horizon of $3^{1} / 2$ quarters because forecasts are made at the middle of each quarter. As pointed out before, we refer to this forecast horizon as 3 quarters.

${ }^{27}$ With real time data, it is around February $15^{\text {th }}$.
} 
where $\varepsilon_{t, 4}$ is the innovation in the fourth quarter of year $t$ which is assumed to be normally distributed with zero mean and a time varying conditional variance. Note that

$$
\pi_{t, 4}^{f}=\beta_{0}+\beta_{1} \pi_{t, 3}^{f}+\beta_{2} \pi_{t, 2}^{f}+\beta_{3} \pi_{t, 1}^{f}+\beta_{4} \pi_{t-1,4}
$$

where all forecasts are made in the first quarter of year $t$. Note that $\pi_{t-1,4}$ is known to forecasters at that time. Based on above assumptions, we have

$$
e_{t, 4}=\pi_{t, 4}-\pi_{t, 4}^{f}=\beta_{1} e_{t, 3}+\beta_{2} e_{t, 2}+\beta_{3} e_{t, 1}+\varepsilon_{t, 4}
$$

Similarly, we have

$$
\begin{aligned}
& e_{t, 3}=\pi_{t, 3}-\pi_{t, 3}^{f}=\beta_{1} e_{t, 2}+\beta_{2} e_{t, 1}+\varepsilon_{t, 3} \\
& e_{t, 2}=\pi_{t, 2}-\pi_{t, 2}^{f}=\beta_{1} e_{t, 1}+\varepsilon_{t, 2} \\
& e_{t, 1}=\pi_{t, 1}-\pi_{t, 1}^{f}=\varepsilon_{t, 1}
\end{aligned}
$$

By successive substitution, we have

$$
e_{t, i}=\sum_{j=1}^{i} b_{j-1} \varepsilon_{t, i-j+1}
$$

where $b_{j}=\beta_{1} b_{j-1}+\ldots+\beta_{4} b_{j-4}, b_{0}=1$ and $b_{j}=0$ for $j<0$.

So, the forecast uncertainty conditional on information set in the first quarter of year $t$ is

$$
W_{t 3}=\operatorname{var}\left(e_{t} \mid \psi_{t, 1}\right)=\operatorname{var}\left(e_{t, 4}+e_{t, 3}+e_{t, 2}+e_{t, 1} \mid \psi_{t, 1}\right)=\sum_{k=1}^{4}\left(\sum_{j=0}^{4-k} b_{j}\right)^{2} E\left(\varepsilon_{t, k}^{2} \mid \psi_{t, 1}\right)
$$


where $\psi_{t, 1}$ denotes the information set in the first quarter of year $t .{ }^{28} W_{t h}$ denotes the forecast uncertainty for annual inflation rate in year $t$ with horizon of $h$ quarters. It is comparable to $\hat{U}_{t h}$, the survey forecast uncertainty for annual inflation in year $t$ with horizon of $h$ quarters. $W_{t h}$ with horizon other than three quarters can be derived similarly.

Figures $3 a-3 d$ compare the survey forecast uncertainty $\hat{U}_{t h}{ }^{29}$ with time series uncertainty $W_{\text {th }}$ for different forecast horizons. ${ }^{30}$ The time profiles and the levels are quite similar after late 1980s. The correlations between these two series are very high after 1984 (for all forecast horizons, the correlation coefficients are above 0.8). During this period, the inflation rate is relatively low and stable. However, the correlation coefficients are quite low before 1984, see table 7. This period is notable for high and volatile inflation. It seems that the two measures give similar results when the inflation process is stable. On the other hand, they diverge when there are structural breaks in the inflation process. This is understandable since ARCH-type models assume that the regime for inflation and inflation uncertainty is invariant over time while survey forecasters surely try to anticipate structural breaks when they make forecasts. ${ }^{31}$ Although these two measures have very low correlation in the earlier period, both of them were sensitive to the effects of the first oil shock in 1973-74, and the second oil shock and the change in the monetary rule in 1979-80 and 1981-82 respectively. During these periods, both measures reported big surges. For the survey measure, by looking at Figure $2 b$, we find that the increase is mostly due to the increase in the forecast disagreement. This again justifies the inclusion of the forecast disagreement into inflation uncertainty. As Kurz (2002) has argued, when

\footnotetext{
${ }^{28}$ Baillie and Bollerslev (1992) derived the formula for calculating $E\left(\varepsilon_{t, k}^{2} \mid \psi_{t, 1}\right)$ for GARCH models. Similar formula for ARCH(4) and GJR-GARCH(1,1) can be found in Engle and Kraft (1983) and Blair, Poon and Taylor (2001) respectively.

${ }^{29}$ As noted before, we keep horizon effects when we compare survey measure with time series measure.

${ }^{30}$ Time series measures of uncertainty in Figure $3 \mathrm{a}-3 \mathrm{~d}$ is estimated and forecasted with $\operatorname{GARCH}(1,1)$ model. Although GJR-GARCH(1,1) model has a better fit to the most recent data as found in table 4, The profile of uncertainty over time are quite similar for these two models. For comparison with models in later part of the paper, we report the results from GARCH $(1,1)$ model rather than GJR-GARCH $(1,1)$ model.

${ }^{31}$ With a Markov switching model, Evans and Wachtel (1993) estimated the regime uncertainty. According to their finding, regime uncertainty was low and stable after 1984 but high and volatile during 1968 to 1983. Although they use in sample forecast based on revised data, their finding shows that the divergence between survey measures and ARCH-type measures is due to the omission of regime uncertainty from the latter.
} 
important policies are enacted, heterogeneity in beliefs creates disagreement in forecasts that in turn contributes to the overall economic uncertainty.

To better understand the divergence between the survey measure and time series measures, we examined the point forecasts produced by the SPF data ${ }^{32}$ and $\operatorname{GARCH}(1,1)$. Figure $4 \mathrm{a}$ shows the point forecasts estimated by these two methods. It is obvious that before 1984, the point forecasts estimated by the two methods are much more different than those after 1984. On average, the sum of absolute value of difference between these two methods is $100 \%$ larger before 1984 than after 1984 . Figure $4 \mathrm{~b}$ shows the absolute forecast errors (forecast - actual) from these two methods. It is very obvious that from mid 1970s to early 1980s, the GARCH point forecasts missed the actual inflation rates substantially. The average absolute forecast errors for the AR (4) model is 1.21 during 1968-1983 (1.41 during 1973-1983) but only 0.39 during 1984-2003. ${ }^{33}$ The same for the survey measure is 1.0 during 1968-1983 (1.11 during 1973-1983) and 0.51 during 19842003. It seems that when there are structural breaks, the survey measure does better than the time series models in forecasting inflation while during a period of low and stable inflation, the latter does better. Since uncertainties based on ARCH-type models are functions of forecast errors, it is not surprising to find that ARCH-type uncertainties are bigger than the survey measure during mid 1970s and early 1980s as revealed in Figures 3a-3d. This may also explain why the survey measure of uncertainty is bigger than ARCH-type uncertainties from mid 1980s to early 1990s for two and one quarter-ahead forecasts.

Another undesirable feature of Figures $3 \mathrm{a}-3 \mathrm{~d}$ is that the $\mathrm{GARCH}(1,1)$ measure has big spikes in 1975 and 1976. This problem is especially serious for four-quarter ahead forecasts. This may be due to the interaction between forecast errors and model parameters. Notice that due to the effect of the first oil shock, $\operatorname{GARCH}(1,1)$ reports big forecast errors in 1974 and 1975. Actually the two largest forecast errors for the whole

\footnotetext{
${ }^{32}$ Consensus forecast of our sample of regular forecasters who participated at least 12 surveys.

${ }^{33}$ The quarters for which the survey measure is missing are not included when calculating the average of absolute forecast errors for $\operatorname{GARCH}(1,1)$.
} 
sample period occurred in these two years. ${ }^{34}$ Consequently, as a result of the GARCH specification big forecast errors will show up as big forecast uncertainty in the following years. That is why we have big forecast uncertainty in 1975 and 1976. One simple way to correct this problem is just to dummy out the several quarters that have large forecast errors. Actually, just dummying out the first and second quarters of 1975 will reduce the spike in 1976 significantly. But this is only an ex post solution. Another explanation for the spikes in 1975 and 1976 is that $\operatorname{GARCH}(1,1)$ exaggerates people's responses to past forecast errors. Considering this, we modified the standard $\operatorname{GARCH}(1,1)$ model by formulating the conditional variance as a function of lagged conditional variance and absolute forecast error (instead of squared forecast error). ${ }^{35}$ This method worked very well to reduce the spikes in 1975 and 1976, especially for long horizon forecast uncertainty. Figures 5a-5d report forecast uncertainty estimated with this modified GARCH $(1,1)$ model and it is obvious that the big spike in 1976 is reduced by more than $50 \%$ for four-quarter ahead forecasts. We also examined the correlation between the survey measure and the measure based on this modified $\operatorname{GARCH}(1,1)$. Although it is still much smaller during 1968-1983 than during 1984-2003, there is significant improvement from standard GARCH$(1,1)$, especially for the earlier period. Actually, as showed in table 7, this model performs better than other models in the sense of reproducing the survey measure.

Above analysis implies that a time series model that takes account of structural breaks may match the survey measure better if the structural breaks are correctly specified. One possible candidate is a model proposed by Evans $(1991)^{36}$, in which the parameters in the mean equation of the ARCH models are allowed to vary over time. Evans proposes three measures of inflation forecast uncertainty, one of which is the sum of conditional variance of innovation to inflation process and the parameter uncertainty. To see if this

\footnotetext{
${ }^{34}$ Four-quarter ahead forecast for annual inflation in 1974 and three-quarter ahead forecast for annual inflation in 1975.

${ }^{35}$ Taylor (1986) and Schwert (1989a, b) modeled conditional standard deviation as a distributed lag of absolute residuals. However, we found that their models could not reduce the spikes in 1975 and 1976.

${ }^{36}$ As pointed out by Evans and Wachtel (1993), this model still fails to account for the effect of anticipated future shifts in inflation regime. They suggest a Markov switching model to explain the structural break in inflation process caused by changing regimes. One direction for future research is to generalize their model to multi-period real time forecasts.
} 
formulation helps to match the survey and times series measures of inflation forecast uncertainty, we estimated the model and obtained forecasts using real time data recursively. Specifically, the model can be written as:

$$
\pi_{t+1}=x_{t} \beta_{t+1}+\varepsilon_{t+1} \quad \varepsilon_{t+1} \sim N\left(0, h_{t+1}\right)
$$

and $x_{t}=\left[1, \pi_{t-1}, \pi_{t-2}, \pi_{t-3}, \pi_{t-4}\right], \quad \beta_{t+1}=\beta_{t}+V_{t+1}, \quad V_{t+1} \sim N(0, Q)$

where $V_{t+1}$ is a vector of normally distributed shocks to the parameter vector $\beta_{t+1}$ with a homoskedastic diagonal covariance matrix $Q$. For the theoretical and empirical arguments for the random walk formulation, see Evans (1991) and Engle and Watson (1985). This model can be written in state space form and estimated with the Kalman Filter.

Observation equation: $\pi_{t+1}=\left(\begin{array}{ll}x_{t} & 1\end{array}\right)\left(\begin{array}{l}\beta_{t+1} \\ \varepsilon_{t+1}\end{array}\right)+\omega_{t+1} \quad$ where $\omega_{t+1}=0$

State equation: $\left(\begin{array}{c}\beta_{t+1} \\ \varepsilon_{t+1}\end{array}\right)=\left(\begin{array}{ll}I & 0 \\ 0 & 0\end{array}\right)\left(\begin{array}{c}\beta_{t} \\ \varepsilon_{t}\end{array}\right)+\left(\begin{array}{c}V_{t+1} \\ \varepsilon_{t+1}\end{array}\right)$

The above model is actually a special case of the unobserved component time series model with ARCH disturbances discussed in Harvey, Ruiz and Sentana (1992). As pointed out by these authors, with time varying parameters, past forecast errors and conditional variances are no longer in the information sets of forecasters and must be inferred from the estimation of the state. They suggest a way to deal with this problem. Following their method, we estimated the above model using real time quarterly inflation data recursively. ${ }^{37}$ The result is shown in Figure 6 for current quarter forecasts. We find that the estimated inflation forecast uncertainty from a time varying parameter GARCH

\footnotetext{
${ }^{37}$ Kim and Nelson (1998) provide a GAUSS program for estimating this model. We adapt their program to get one-period-ahead forecasts. We want to express our thanks to them.
} 
model is smaller than that estimated from the ordinary GARCH model during the mid 1970s. This result suggests that the divergence between time series measures and survey measures may be resolved to a great extent by generalizing the time series models that take into account explicitly the structural breaks and parameter drift.

\section{Inflation Uncertainty using VAR-ARCH models}

Univariate $\mathrm{ARCH}$ model and its extensions formulate inflation as a function only of its own past values. This assumption ignores the interactions between inflation and other variables that can be used to forecast inflation. However, as Stock and Watson (1999) have demonstrated, some macroeconomic variables can help improve inflation forecast. Among these variables, they find that inflation forecasts produced by the Phillips curve generally have been more accurate than forecasts based on other macroeconomic variables, such as interest rates, money supply and commodity prices. In this section, we investigate if other macroeconomic variables help to match the survey measure and time series measures of inflation forecast uncertainty. Considering the availability of real time data, we will use the traditional Phillips curve based on unemployment. ${ }^{38}$ The forecasting model of inflation then becomes

$$
\pi_{t}=\beta_{0}+\beta_{1} \pi_{t-1}+\beta_{2} \pi_{t-2}+\beta_{3} \pi_{t-3}+\beta_{4} \pi_{t-4}+\delta_{1} u_{t-1}+\delta_{2} u_{t-2}+\delta_{3} u_{t-3}+\delta_{4} u_{t-4}+\varepsilon_{t}
$$

where, $\pi_{t}, u_{t}$ and their lags are quarterly data on inflation and unemployment rates. To test for the presence of conditional heteroscedasticity in the form of $\mathrm{ARCH} / \mathrm{GARCH}$ process, we estimate (7-1) by OLS over the sample period from 1955Q2 to 2004Q2 released in 2004Q3. The squared residuals were then regressed on it's own lags up to 20. The $\chi^{2}$ test found a significant ARCH/GARCH effect at the $1 \%$ level. ${ }^{39}$ One problem with forecasting inflation by (7-1) is that we need to first forecast unemployment rate

\footnotetext{
${ }^{38}$ This is the only variable available in real time data set at the Federal Reserve bank of Philadelphia web site as a measure of output gap.

${ }^{39}$ The value of test statistic $T R^{2}$ was 38.52 . The critical value for $\chi^{2}$ test with 20 degree of freedom is 31.4 at significance level $1 \%$.
} 
when the forecast horizon is more than one period. This problem can be solved by modeling unemployment also as an $\mathrm{AR}(4)$ process:

$$
u_{t}=\delta_{0}+\delta_{1} u_{t-1}+\delta_{2} u_{t-2}+\delta_{3} u_{t-3}+\delta_{4} u_{t-4}+v_{t}
$$

Putting (7-1) and (7-2) together, we model inflation and unemployment as VAR(G)ARCH processes.

$$
\left(\begin{array}{l}
\pi_{t} \\
u_{t}
\end{array}\right)=\left(\begin{array}{l}
\beta_{0} \\
\gamma_{0}
\end{array}\right)+\left(\begin{array}{cc}
\beta_{1} & \delta_{1} \\
0 & \gamma_{1}
\end{array}\right)\left(\begin{array}{l}
\pi_{t-1} \\
u_{t-1}
\end{array}\right)+\cdots+\left(\begin{array}{cc}
\beta_{4} & \delta_{4} \\
0 & \gamma_{4}
\end{array}\right)\left(\begin{array}{l}
\pi_{t-4} \\
u_{t-4}
\end{array}\right)+\left(\begin{array}{c}
\varepsilon_{t} \\
v_{t}
\end{array}\right)
$$

or compactly $Z_{t}=A_{0}+A_{1} Z_{t-1}+\cdots+A_{4} Z_{t-4}+\mu_{t}, \quad$ where $Z_{t}=\left(\begin{array}{l}\pi_{t} \\ u_{t}\end{array}\right), \quad \mu_{t}=\left(\begin{array}{c}\varepsilon_{t} \\ v_{t}\end{array}\right)$. Innovations in the inflation equation are assumed to have a time varying conditional variance. Specifically, we assume

$E\left(\mu_{t} \mid \psi_{t-1}\right)=0$ and $\operatorname{var}\left(\mu_{t} \mid \psi_{t-1}\right)=H_{t}=\left(\begin{array}{cc}\sigma_{t}^{2} & \rho_{\varepsilon v} \sigma_{\nu} \sigma_{t} \\ \rho_{\varepsilon v} \sigma_{v} \sigma_{t} & \sigma_{v}^{2}\end{array}\right)$,

where $\sigma_{t}^{2}=E\left(\varepsilon_{t}^{2} \mid \psi_{t-1}\right)=h\left(\varepsilon_{t-1}, \ldots, \sigma_{t-1}^{2}, \ldots\right), \sigma_{v}^{2}=E\left(v_{t}^{2} \mid \psi_{t-1}\right)=E\left(v_{t}^{2}\right)$ and $E\left(\varepsilon_{t} v_{t} \mid \psi_{t-1}\right)=\sigma_{\varepsilon v t}=\rho_{\varepsilon v} \sigma_{v} \sigma_{t}$.

Following Bollerslev(1990), we assume constant conditional correlation coefficient to simplify ML estimation. Assuming conditional normality, the model can be estimated as described in that paper. Tables 5 and 6 show the estimates of VAR-ARCH(1) and VAR$\operatorname{GARCH}(1,1)$ over the same sample as before.

As in the previous section, if the target variable is annual inflation rate forecasted at different horizons, the forecast error is the sum of corresponding forecast errors for the quarterly variables. Consider the forecast made in the first quarter of year $t$. The forecast 
errors for the vector of quarterly inflation and quarterly unemployment rate in the four quarters of year $t$ are $e_{t, 1}=\mu_{t, 1}, \quad e_{t, 2}=A_{1} e_{t, 1}+\mu_{t, 2}, \quad e_{t, 3}=A_{1} e_{t, 2}+A_{2} e_{t, 1}+\mu_{t, 3} \quad$ and $e_{t, 4}=A_{1} e_{t, 3}+A_{2} e_{t, 2}+A_{3} e_{t, 1}+\mu_{t, 4}$, where $X_{t, i}$ denotes the value of $X$ in the $i^{t h}$ quarter of year $t$.

By successive substitution, we have

$$
e_{t, i}=\sum_{j=1}^{i} B_{j-1} \mu_{t, i-j+1}
$$

where $B_{j}=A_{1} B_{j-1}+\ldots+A_{4} B_{j-4}, B_{0}=I, B_{j}=0$ for $j<0$.

After some tedious algebra, it can be shown that the forecast error for quarterly inflation in the $i^{\text {th }}$ quarter of year $t$ is

$$
e_{t, i}^{\pi}=\sum_{j=1}^{i} b_{j-1} \varepsilon_{t, i-j+1}+\sum_{j=1}^{i} \lambda_{j-1} v_{t, i-j+1}
$$

where $b_{j}$ is defined as in (6-14) and $\lambda_{j}=\sum_{k=0}^{3} d_{k} b_{j-k}$

$d_{k}=\delta_{1} c_{k-1}+\ldots+\delta_{4} c_{k-4}$ with $d_{0}=0$

$c_{j}=\gamma_{1} c_{j-1}+\ldots+\gamma_{4} c_{j-4}$ with $c_{0}=1$ and $c_{j}=0$ for $\mathrm{j}<0$

So, the forecast uncertainty of annual inflation conditional on the information set in the first quarter of year $t$ is ${ }^{40}$

\footnotetext{
${ }^{40}$ Hlouskova, Schmidheiny and Wagner (2004) derive the general formula for the multi-step minimum mean squared error (MSE) prediction of the conditional means, variances and covariances for multivariate GARCH models with an application in portfolio management.
} 


$$
\begin{aligned}
& W_{t 3}=\operatorname{var}\left(e_{t}^{\pi} \mid \psi_{t, 1}\right)=\operatorname{var}\left(e_{t, 4}^{\pi}+e_{t, 3}^{\pi}+e_{t, 2}^{\pi}+e_{t, 1}^{\pi} \mid \psi_{t, 1}\right) \\
& =\sum_{k=1}^{4}\left(\sum_{j=0}^{4-k} b_{j}\right)^{2} E\left(\varepsilon_{t, k}^{2} \mid \psi_{t, 1}\right)+\sum_{k=1}^{3}\left(\sum_{j=0}^{4-k} \lambda_{j}\right)^{2} E\left(v_{t, k}^{2} \mid \psi_{t, 1}\right) \\
& +2 \rho_{\varepsilon v} \sum_{k=1}^{3}\left(\sum_{j=0}^{4-k} \lambda_{j}\right)\left(\sum_{j=0}^{4-k} b_{j}\right) \sqrt{E\left(\varepsilon_{t, k}^{2} \mid \psi_{t, 1}\right) E\left(v_{t, k}^{2} \mid \psi_{t, 1}\right)}
\end{aligned}
$$

We could derive the equation for calculating forecast uncertainty for other forecast horizons similarly.

Table 7 shows the simple correlation of the survey measure with different time series measures. Some interesting conclusions may be drawn from this table. First, on average GARCH models simulate the survey measure better than ARCH models. The average correlations over different forecast horizons are 0.354 and 0.322 for VAR-ARCH(1) and $\mathrm{ARCH}(4)$ respectively, much lower than the correlations for corresponding VAR$\operatorname{GARCH}(1,1)$ and $\operatorname{GARCH}(1,1)$ models, which were 0.465 and 0.447 respectively. It confirms the finding in the literature that changes in the conditional variance of inflation persist over time. Actually, one motivation of developing GARCH model is to provide a better formulation to capture this feature of inflation data (Bellerslev(1986)). Second, univariate models perform as well as bivariate models in simulating the survey measure of uncertainty. This may be quite surprising at first glance since it is well documented that the Phillips curve provides a better point forecast of inflation than autoregressive models of inflation. Ericsson (2003) discusses various determinants of forecast uncertainty. He points out that forecast uncertainty depends upon the variable being forecast, the type of model used for forecasting, the economic process actually determining the variable being forecast, the information available, and the forecast horizon. He also differentiates between actual forecast uncertainty and anticipated forecast uncertainty, which is model dependent. In our problem, the difference between forecast uncertainty from univariate models and that from multivariate models lies only in the difference in model specification since they have the same target variable, same data generating process, same information set and same forecast horizon. As explained by Ericsson, it is not surprising that different models will produce different anticipated forecast uncertainty. Third, models that allow for asymmetric effects of positive and 
negative innovations came closer to the survey measure better than models that do not. Actually, among the six models we report, GJR-GARCH(1,1) has the second highest average correlation with the survey measure of uncertainty. Fourth, our modified $\operatorname{GARCH}(1,1)$ model is the best in terms of correlation with the survey measure. As discussed in section 6 , this is because it modifies the GARCH specification by replacing squared past errors with absolute errors. Finally, for all models, the correlation of uncertainty of the two approaches is quite high for the period 1984-2003, a period with low and stable inflation, but low for the period 1969-1983, a period notable for high and unstable inflation. Actually, the relative performance of different models in simulating the survey measure depends on how well it can simulate the survey measure during 19681983. For example, the correlation with the survey measure is relatively high for GJR$\operatorname{GARCH}(1,1)$ and modified $\operatorname{GARCH}(1,1)$ in this period. As discussed in section 5, our empirical estimate of the sum of the forecast disagreement and the average individual forecast uncertainty indirectly captures model uncertainty by incorporating the forecast disagreement. But the time series models discussed in this paper is based on a single model to produce forecast uncertainty for all periods. This may explain the big divergence of these two types of measures during periods with high model uncertainty.

\section{Conclusions}

In this paper, we develop a theoretical model to study the relationship between different measures of inflation forecast uncertainty based on survey data and aggregate time series models. We found that the sum of the average variance of the individual densities and the disagreement slightly underestimates forecast uncertainty based on aggregate time series data, and this underestimation is a function of the ratio of the variance of aggregate shocks to that of the idiosyncratic shocks. Given the existing empirical estimates of the ratio, we expect the underestimation to be minimal.

Even though the sum of the average variance and the disagreement is simply the variance of the average density, we cannot directly use the variance of the aggregate distribution to measure the aggregate forecast uncertainty due to grouping data problems, and 
compositional effects in the panel. In this paper we lay out a tedious procedure to extract the conceptually correct measure of aggregate uncertainty from the panel of density forecasts.

The SPF density forecast data have an accordion structure where each respondent forecasts year-over-year inflation rate every quarter in the current year. In order to compare the forecast uncertainty from the surveys with those from the quarterly time series data at various horizons, we developed the appropriate multi-period forecast variance formulas for multivatiate ARCH-type models. During normal times (19842002), the survey uncertainty and the ARCH-based time series uncertainty were remarkably similar in their average values, correlations and temporal movements. Another finding of our analysis is that the univariate asymmetric GARCH model did as well as the bivariate GARCH model with Phillips Curve.

During periods of rapid structural change (like the oil crises or Fed's new operating policies of early 80 's), we found that the two approaches could yield quite different estimates of uncertainty. Since these periods are characterized by larger forecast errors in time series models than in survey data, the time series uncertainty shoots up much more than the survey measure. During periods of rapid change, it is the disagreement component of uncertainty and not the average variance of the densities that responds, but not by as much as the time series uncertainty. We found a simple way to make the time series estimates robust to exceptionally large forecast errors; the trick is to model the conditional variance not as a function of squared forecast errors but as a function of its absolute value.

Another fruitful approach will be to model the time series ARCH model as a time varying parameter model. We found that this approach also helps in robustifying $\mathrm{ARCH}$ uncertainty estimates to abrupt structural breaks. Even then, the survey uncertainty tends to respond more prospectively than time series models. Thus, during periods of structural breaks and regime change, survey measure of uncertainty can be very dependable, and should be monitored carefully in conjunction with the time series measures. This reminds 
us of the sentiment Manski (2004) expressed when he wrote, "Economists have long been hostile to subjective data. Caution is prudent but hostility is not warranted." Our analysis shows that by carefully utilizing the SPF density forecasts data, we can gather substantial knowledge about the temporal pattern of aggregate uncertainty of inflation forecasts, particularly when time series models could be failing. There remains much unexploited potential in the use of this subjective database. 


\section{References}

Baillie, R.T. and T. Bollerslev (1992), "Prediction in dynamic models with timedependent conditional variance", Journal of Econometrics, 52, 91-113.

Ball, L. (1992), "Why does high inflation raise inflation uncertainty?" Journal of Monetary Economics, 371-388.

Ball, L. and N.G. Mankiw (1995), "Relative-price changes as aggregate supply shocks", Quarterly Journal of Economics, 110, 161-193.

Batchelor, R. and P. Dua (1993), "Survey vs. ARCH measures of uncertainty", Oxford Bulletin of Economics and Statistics, 55, 341-353.

Batchelor, R. and P. Dua (1995), "Forecaster diversity and the benefits of combining forecasts", Management Science, 41, 68-75.

Batchelor, R. and P. Dua (1996), "Empirical measures of inflation uncertainty: a cautionary note", Applied Economics, 28, 333-341.

Bera, A.K. and Higgins, M.L. (1993), "ARCH models: properties, estimation and testing", Journal of Economic Surveys, 7, 305-362.

Blair B.J., S.H. Poon and S.J. Taylor (2001), "Forecasting S\&P 100 volatility: the incremental information content of implied volatilities and high-frequency index return", Journal of econometrics, 105, 5-26.

Bollerslev, T. (1986), "Generalized autoregressive conditional heteroscedasticity", Journal of Econometrics, 31, 307-327. 
Bollerslev, T. (1990), "Modeling the coherence in short-run nominal exchange rates: A multivariate generalized ARCH model", Review of Economics and Statistics, 72, 498505.

Bollerslev, T., Chou, R.Y. and K.P. Kroner (1992), "ARCH modeling in finance: a review of theory and empirical evidence", Journal of Econometrics, 52, 5-59.

Bomberger, W.A. (1996), "Disagreement as a measure of uncertainty", Journal of Money, Credit and Banking, 28, 381-392.

Carroll, C.D. (2003), "Macroeconomic expectations of households and professional forecasters", Quarterly Journal of Economics, 118, 269-298.

Christofferson, P.F., and F.X. Diebold (1997), “Optimal prediction under asymmetric loss", Econometric Theory, 13, 808-817.

Cogley, T., S. Morozov and T. J. Sargent (2003), "Bayesian Fan Charts for U.K. Inflation: Forecasting and Sources of Uncertainty in an Evolving Monetary System", Draft, July 2003.

Croushore, D. and T. Stark (2001), "A real-time data set for macroeconomists", Journal of econometrics, 105, 111-130.

Cukierman, A. and P. Wachtel (1979), "Differential inflationary expectations and the variability of the rate of inflation: theory and evidence ", American Economic Review, 69, 595-609.

Cukierman, A. and P. Wachtel (1982), "relative price variability and nonuniform inflationary expectations ”, Journal of Political Economy, 90, 146-157. 
Davies, A. and K. Lahiri (1995), “A new framework for analyzing survey forecasts using three-dimensional panel data", Journal of Econometrics, 68, 205-227.

Davies, A. and K. Lahiri (1999), "Re-examining the rational expectations hypothesis using panel data on multi-period forecasts" In Hsiao, C., Lahiri, K., Lee, L.F. and Pesaran, H. (Eds.) Analysis of Panels and Limited Dependent Variable Models. Cambridge: Cambridge University Press.

Diebold, F., A. Tay and K. Wallis (1999), "Evaluating Density Forecasts of Inflation:

The Survey of Professional Forecasters," in R. Engle and H. White (eds.), Cointegration, Causality, and Forecasting: A Festschrift in Honor of Clive W.J. Granger, 76-90, 1999.

Oxford: Oxford University Press.

Engle, R. (1982), “Autoregressive conditional heteroscedasticity with estimates of the variance of United Kingdom inflation”, Econometrica, 50, 987-1008.

Engle, R. (1983), "Estimates of the variance of U.S. inflation based upon the ARCH model", Journal of Money, Credit and Banking, 15, 286-301.

Engle, R.F. and D. Kraft (1983), "Multiperiod forecast error variances of inflation estimated from ARCH models", in: A. Zellner, ed., Applied time series analysis of economic data (Bureau of the Census, Washington, DC), 293-302.

Engle, R. F. and Watson, M.W. (1985), “The Kalman filter: applications to forecasting and rational-expectations models" in: Truman Bewley, ed., Advances in econometrics, Vol. I, Fifth World Congress of the Econometric Society.

Ericsson, N.R. (2003), "Forecast uncertainty in economic modeling" In understanding economic forecasts, edited by David F. Hendry and Neil R. Ericsson, 68-92, Cambridge and London, MIT Press. 
Evans, M. (1991), "Discovering the link between inflation rates and inflation uncertainty", Journal of Money, Credit and Banking, 23, 169-184.

Evans, M. and P. Wachtel (1993), "Inflation regimes and the sources of inflation uncertainty", Journal of Money, Credit and Banking, 25, 475-511.

Friedman, M. (1977), "Nobel Lecture: inflation and unemployment", The Journal of Political Economy, 85, 451-472.

Fuhrer, J.C., (1988), "On the information content of consumer survey expectations", Review of Economics and Statistics, 70, No. 1, 140-144.

Fukford, S.L. (2002), "The Impact of monetary policy on the cross-sectional variance of expectations of inflation", Stanford University, mimeo.

Garratt, A., K. Lee, M. H. Pesaran and Y. Shin (2003), "Forecast uncertainty in macroeconomic modelling: an application to the U.K. ecomomy", Journal of the American Statistical Association, 98, 829-838.

Giordani, P. and P. Söderlind (2003), "Inflation forecast uncertainty", European Economic Review, 47, 1037-1059.

Glosten, L., R. Jagannathan, and D. Runkle (1993), "On the relation between the expected value and the volatility of the nominal excess return on stocks", Journal of Finance, 48, 1779-1801.

Greene, W.H., Econometric Analysis, $4^{\text {th }}$ Edition, Prentice Hall, Upper Saddle River, New Jersey, 2000.

Harvey A., E. Ruiz and E. Sentana (1992), "Unobserved component time series models with ARCH disturbances", Journal of Econometrics 52, 129-157. 
Hlouskova J., K. Schmidheiny and M. Wagner (2004), "Multistep predictions for multivariate GARCH models: closed form solution and the value for portfolio management", Draft, 2004.

Irwin, S.H., M.E. Gerlow and T.R. Liu (1994), "The forecasting performance of livestock futures prices: a comparison of USDA expert predictions", Journal of Futures Markets, $14,861-875$.

Kastens, T. L., T.C. Schroeder and R. Plain (1998), "Evaluation of extension and USDA price and production forecasts", Journal of Agricultural and Resource Economics, 23, 244-261.

Kim, C.-J. and C.R. Nelson (1998), State-Space Model with Regime-Switching: Classical and Gibbs-sampling Approaches with Applications, MIT Press: Cambridge, MA.

Kurz, M. (2002), “Heterogeneous forecasting and Federal Reserve information”, Stanford University, 2002, mimeo.

Kurz, M. and M. Motolese (2001), "Endogenous uncertainty and market volatility", Economic Theory, 17, 497-544.

Lahiri, K., and D. Ivanova (1998), "A time series and cross sectional analysis of consumer sentiment and its components", In Social Structural Change - Consequences for Business Cycle Surveys, (Eds. K. H. Oppenländer and G. Poser), Aldershot: Ashgate Publishing, England, 337-362.

Lahiri, K. and C. Teigland (1987), “On the normality of probability distribution and GNP forecasts", International Journal of Forecasting, 3, 269-279. 
Lahiri, K., C. Teigland and M. Zaporowski (1988), "Interest rates and the subjective probability distribution of inflation forecasts", Journal of Money, Credit and Banking, 20, 233-248.

Laster, D., P. Bennett and I.S. Geoum (1999), "Rational bias in macroeconomic forecast", The Quarterly Journal of Economics, 114, 293-318.

Levi, M. and J. Makin (1978), "Anticipated inflation and interest rates: Further interpretation of findings on the Fisher equation", American Economic Review, 68, 801812.

Lucas, R.E. (1972), "Expectations and the neutrality of money", Journal of Economic Theory, 4, 103-124.

Lucas, R.E. (1973), "Some international evidence on output-inflation tradeoffs", American Economic Review, 63, 326-334.

Makin, J. (1983), "Real interest, money surprises, anticipated inflation, and fiscal deficits", Review of Economics and Statistics, 65, 374-384.

Mankiw, N.G., R. Reis and J. Wolfers (2003), "Disagreement about inflation expectation", NBER Working Paper No. w9796.

Mankiw, N.G., R. Reis (2002), "Sticky information versus sticky prices: a proposal to replace the new Keynesian Phillips curve", Quarterly Journal of Economics, 117, 12951328.

Manski, C.F. (2004), “Measuring expectations”, Econometrica, 72, 1329-1376.

McNees, S. (1989), "Why do forecasts differ", New England Economic Review, Jan./Feb., 42-54. 
Nelson, D.B. (1991), "Conditional heteroskedasticity in asset returns: a new approach", Econometrica, 59, 347-370.

Palm, F., and A. Zellner (1992), "To combine or not to combine? Issue of combining forecasts", Journal of Forecasting, 11, 687-701.

Rich, R. and J. Tracy (2003), "Modeling uncertainty: Predictive accuracy as a proxy for predictive confidence", Federal Reserve Bank of New York Staff Reports, No.161.

Schwert, G.W. (1989a), "Why does stock market volatility change over time", Journal of Finance, 44, 1115-1153.

Schwert, G.W. (1989b), "Business cycles, financial crises, and stock volatility", Carnegie-Rochester Conference Series on Public Policy, 39, 83-126.

Sims, C. (2002), "The role of models and probabilities in the monetary policy process", Brookings Papers on Economic Activity, 2002(2), 1-62.

Šmidková, K. (2003), "Methods available to monetary policy makers to deal with uncertainty", paper presented at the conference "Forecasting in a Central Bank", Bank of England, August 2003, London.

Souleles, N., (2004), "Expectations, heterogeneous forecast errors, and consumption: micro evidence from the Michigan Consumer Sentiment Surveys", Journal of Money, Credit and Banking, 36, 39-72.

Stock, J. and M.W. Watson (1999), "Forecasting inflation", Journal of Monetary Economics, 44, 293-335. 
Stuart, A. and J.K. Ord (1994), Kendall's advanced theory of statistics, voll, John Wiley \& Sons Inc.

Taylor, S. (1986), Modeling Financial Time Series. Wiley and Sons: New York, NY.

Wallis, K.F. (2004), “Combining density and interval forecasts: a modest proposal", Mimeo, October 2004. University of Warwick, UK.

Zarnowitz, V. and L.A. Lambros (1987), "Consensus and uncertainty in economic prediction", Journal of Political Economy, 95, 591-620.

Zellner, A. (1986), Bayesian estimation and prediction using asymmetric loss functions, Journal of the American Statistical Association, 81, 446-451. 
Table 1. Estimates of average horizon effects.

\begin{tabular}{cllll}
\hline variable & Coefficients & Std. Error & t-statistic & p-value \\
\hline$\hat{\alpha}$ & 0.6676 & 0.029 & 23.378 & 0.000 \\
$\hat{\delta}_{3}$ & -0.0006 & 0.023 & -0.025 & 0.98 \\
$\hat{\delta}_{2}$ & -0.0929 & 0.019 & -5.017 & 0.000 \\
$\hat{\delta}_{1}$ & -0.1959 & 0.018 & -10.704 & 0.000 \\
\hline
\end{tabular}


Table 2. GARCH $(1,1)$ estimates.

\begin{tabular}{cllll}
\hline variable & Coefficient & Std. Error & t-statistic & p-value \\
\hline $\mathrm{c}$ & 0.0510 & 0.0288 & 1.7717 & 0.076 \\
$\pi_{t-1}$ & 0.4708 & 0.0767 & 6.1402 & 0.000 \\
$\pi_{t-2}$ & 0.1780 & 0.0811 & 2.1947 & 0.028 \\
$\pi_{t-3}$ & 0.0393 & 0.0826 & 0.4755 & 0.634 \\
$\pi_{t-4}$ & 0.2301 & 0.0712 & 3.2316 & 0.001 \\
\hline $\mathrm{c}$ & 0.0018 & 0.0013 & 1.3556 & 0.175 \\
$\varepsilon_{t-1}^{2}$ & 0.1278 & 0.0482 & 2.6536 & 0.008 \\
$h_{t-1}$ & 0.8439 & 0.0535 & 15.7737 & 0.000 \\
\hline
\end{tabular}

$R^{2}=0.807 ;$ Log Likelihood $=5.005 ; \mathrm{AIC}=0.000 ; \mathrm{SC}=0.084$

Table 3. ARCH(4) estimates.

\begin{tabular}{cllll}
\hline variable & Coefficient & Std. Error & t-statistic & p-value \\
\hline $\mathrm{c}$ & 0.0567 & 0.0374 & 1.5175 & 0.129 \\
$\pi_{t-1}$ & 0.4372 & 0.0746 & 5.8574 & 0.000 \\
$\pi_{t-2}$ & 0.2252 & 0.1171 & 1.9237 & 0.054 \\
$\pi_{t-3}$ & 0.0325 & 0.1058 & 0.3069 & 0.759 \\
$\pi_{t-4}$ & 0.2147 & 0.0762 & 2.8193 & 0.005 \\
\hline $\mathrm{c}$ & 0.0185 & 0.0067 & 2.7713 & 0.006 \\
$\varepsilon_{t-1}^{2}$ & 0.2038 & 0.1393 & 1.4625 & 0.144 \\
$\varepsilon_{t-2}^{2}$ & 0.1482 & 0.1341 & 1.1052 & 0.269 \\
$\varepsilon_{t-3}^{2}$ & 0.1547 & 0.0852 & 1.8154 & 0.069 \\
$\varepsilon_{t-4}^{2}$ & 0.2677 & 0.1242 & 2.1557 & 0.031 \\
\hline$R^{2}=0.795 ;$ Log Likelihood=2.341; AIC $=0.027 ; \mathrm{SC}=0.111$ &
\end{tabular}


Table 4. GJR-GARCH( $(1,1)$ estimates.

\begin{tabular}{cllll}
\hline variable & Coefficient & Std. Error & t-statistic & p-value \\
\hline $\mathrm{c}$ & 0.0567 & 0.0273 & 2.0784 & 0.038 \\
$\pi_{t-1}$ & 0.5018 & 0.0820 & 6.1173 & 0.000 \\
$\pi_{t-2}$ & 0.1621 & 0.0854 & 1.8982 & 0.058 \\
$\pi_{t-3}$ & 0.0195 & 0.0817 & 0.2383 & 0.812 \\
$\pi_{t-4}$ & 0.2454 & 0.0690 & 3.5574 & 0.000 \\
\hline $\mathrm{c}$ & 0.002 & Variance Equation & \\
\hline$\varepsilon_{t-1}^{2}$ & 0.2127 & 0.0013 & 1.5954 & 0.111 \\
$h_{t-1}$ & 0.8546 & 0.0869 & 2.4473 & 0.014 \\
$D_{t-1} \varepsilon_{t-1}^{2}$ & -0.2127 & 0.0746 & 11.4614 & 0.000 \\
\hline$R^{2}$ & & 0.0831 & -2.5606 & 0.010 \\
\hline $0.810 ; \mathrm{L} 0 g \mathrm{Lik}$ & & & \\
\hline
\end{tabular}

$R^{2}=0.810 ;$ Log Likelihood=10.614; $\mathrm{AIC}=-0.058 ; \mathrm{SC}=0.026$ 
Table 5 VAR-ARCH(1) estimates

\begin{tabular}{ccccc}
\hline Variable & Coefficient & Std. Error & t-statistic & p-value \\
\hline Equation $\pi_{t}$ & & & & \\
\hline $\mathrm{c}$ & 0.2422 & 0.0705 & 3.4355 & 0.001 \\
$\pi_{t-1}$ & 0.4430 & 0.1027 & 4.3144 & 0.000 \\
$\pi_{t-2}$ & 0.1580 & 0.0758 & 2.0839 & 0.037 \\
$\pi_{t-3}$ & 0.0991 & 0.0785 & 1.2623 & 0.207 \\
$\pi_{t-4}$ & 0.2933 & 0.0805 & 3.6450 & 0.000 \\
$u_{t-1}$ & -0.2967 & 0.0591 & -5.0192 & 0.000 \\
$u_{t-2}$ & 0.2922 & 0.1325 & 2.2058 & 0.027 \\
$u_{t-3}$ & -0.1066 & 0.1535 & -0.6942 & 0.488 \\
$u_{t-4}$ & 0.0691 & 0.0719 & 0.9609 & 0.337 \\
\hline
\end{tabular}

Equation $u_{t}$

\begin{tabular}{ccccc}
\hline $\mathrm{c}$ & 0.2588 & 0.0863 & 3.0003 & 0.003 \\
$u_{t-1}$ & 1.6232 & 0.0713 & 22.7616 & 0.000 \\
$u_{t-2}$ & -0.7117 & 0.1352 & -5.2645 & 0.000 \\
$u_{t-3}$ & -0.0285 & 0.1359 & -0.2099 & 0.834 \\
$u_{t-4}$ & 0.0737 & 0.0719 & 1.0248 & 0.305 \\
\hline Variance-Covariance matrix & & & \\
\hline $\mathrm{c}$ & 0.0368 & 0.0056 & 6.6073 & 0.000 \\
$\varepsilon_{t-1}^{2}$ & 0.4271 & 0.1376 & 3.1028 & 0.002 \\
$\rho_{\varepsilon v}$ & -0.0361 & 0.0757 & -0.4771 & 0.633 \\
$\sigma_{v}$ & 0.2730 & 0.0139 & 19.6454 & 0.000 \\
\hline
\end{tabular}


Table 6 VAR-GARCH $(1,1)$ estimates

\begin{tabular}{ccccc}
\hline Variable & Coefficient & Std. Error & t-statistic & p-value \\
\hline Equation $\pi_{t}$ & & & & \\
\hline $\mathrm{c}$ & 0.2288 & 0.0660 & 3.4651 & 0.001 \\
$\pi_{t-1}$ & 0.3888 & 0.0769 & 5.0543 & 0.000 \\
$\pi_{t-2}$ & 0.2044 & 0.0783 & 2.6107 & 0.009 \\
$\pi_{t-3}$ & 0.0774 & 0.0781 & 0.9913 & 0.322 \\
$\pi_{t-4}$ & 0.3067 & 0.0698 & 4.3925 & 0.000 \\
$u_{t-1}$ & -0.2568 & 0.0599 & -4.2870 & 0.000 \\
$u_{t-2}$ & 0.2245 & 0.1105 & 2.0322 & 0.042 \\
$u_{t-3}$ & 0.0222 & 0.1093 & 0.2027 & 0.839 \\
$u_{t-4}$ & -0.0291 & 0.0569 & -0.5107 & 0.610 \\
\hline
\end{tabular}

Equation $u_{t}$

\begin{tabular}{ccccc}
\hline $\mathrm{c}$ & 0.2585 & 0.0863 & 2.9963 & 0.003 \\
$u_{t-1}$ & 1.6219 & 0.0703 & 23.0717 & 0.000 \\
$u_{t-2}$ & -0.7100 & 0.1264 & -5.6171 & 0.000 \\
$u_{t-3}$ & -0.0299 & 0.1163 & -0.2569 & 0.797 \\
$u_{t-4}$ & 0.0747 & 0.0633 & 1.1802 & 0.238 \\
\hline Variance-Covariance matrix & & & \\
\hline $\mathrm{c}$ & 0.0021 & 0.0017 & 1.2909 & 0.197 \\
$\varepsilon_{t-1}^{2}$ & 0.1627 & 0.0723 & 2.2494 & 0.024 \\
$\sigma_{t-1}^{2}$ & 0.8008 & 0.0852 & 9.4013 & 0.000 \\
$\rho_{\varepsilon v}$ & -0.0260 & 0.0751 & -0.3460 & 0.729 \\
$\sigma_{v}$ & 0.2730 & 0.0139 & 19.6461 & 0.000 \\
\hline
\end{tabular}


Table 7. Correlations of time series and survey measures of uncertainty

\begin{tabular}{|c|c|c|c|c|c|c|c|}
\hline & & $\begin{array}{c}\text { VAR- } \\
\operatorname{GARCH}(1,1)\end{array}$ & $\begin{array}{c}\text { VAR- } \\
\text { ARCH(1) }\end{array}$ & $\begin{array}{c}\text { GJR- } \\
\text { GARCH }(1,1)\end{array}$ & $\operatorname{GARCH}(1,1)$ & $\begin{array}{c}\text { Modified } \\
\operatorname{GARCH}(1,1)\end{array}$ & $\mathrm{ARCH}(4)$ \\
\hline \multirow{3}{*}{$\begin{array}{l}\text { 4Q Ahead } \\
\text { Forecast }\end{array}$} & Whole Sample & $0.642 *$ & 0.297 & 0.384 & 0.427 & 0.530 & 0.317 \\
\hline & 1968-1983 & 0.474* & 0.137 & 0.118 & 0.224 & 0.244 & 0.166 \\
\hline & $1984-2001$ & 0.875 & 0.895 & 0.918* & 0.910 & 0.873 & 0.886 \\
\hline \multirow{3}{*}{$\begin{array}{l}\text { 3Q Ahead } \\
\text { Forecast }\end{array}$} & Whole Sample & 0.528 & 0.566 & 0.690 & 0.584 & 0.701* & 0.429 \\
\hline & 1968-1983 & 0.385 & $0.569 *$ & $0.569 *$ & 0.369 & 0.542 & 0.187 \\
\hline & 1984-2001 & 0.905* & 0.802 & 0.794 & 0.886 & 0.843 & 0.749 \\
\hline \multirow{3}{*}{$\begin{array}{l}\text { 2Q Ahead } \\
\text { Forecast }\end{array}$} & Whole Sample & 0.294 & 0.255 & 0.338 & 0.294 & 0.459* & 0.176 \\
\hline & 1968-1983 & 0.039 & 0.139* & 0.065 & -0.037 & 0.087 & -0.081 \\
\hline & $1984-2001$ & 0.858 & 0.744 & 0.874 & 0.861 & $0.877 *$ & 0.747 \\
\hline \multirow{3}{*}{$\begin{array}{l}\text { 1Q Ahead } \\
\text { Forecast }\end{array}$} & Whole Sample & 0.396 & 0.296 & 0.464 & 0.481 & $0.565 *$ & 0.366 \\
\hline & 1968-1983 & 0.087 & -0.016 & 0.265 & 0.401* & 0.376 & 0.318 \\
\hline & 1984-2001 & 0.887 & 0.801 & 0.922* & 0.870 & 0.840 & 0.750 \\
\hline \multirow{3}{*}{$\begin{array}{c}\text { Average } \\
\text { across } \\
\text { horzions }\end{array}$} & Whole Sample & 0.465 & 0.354 & 0.469 & 0.447 & $0.564 *$ & 0.322 \\
\hline & 1968-1983 & 0.246 & 0.207 & 0.254 & 0.240 & $0.312 *$ & 0.148 \\
\hline & 1984-2001 & 0.881 & 0.811 & 0.877 & 0.882* & 0.858 & 0.783 \\
\hline
\end{tabular}

Note: Numbers with "*” are the highest correlation coefficients among all the six time series models considered. 
Figure 1. the lower bound of the sum of average individual uncertainty and forecast disagree ment

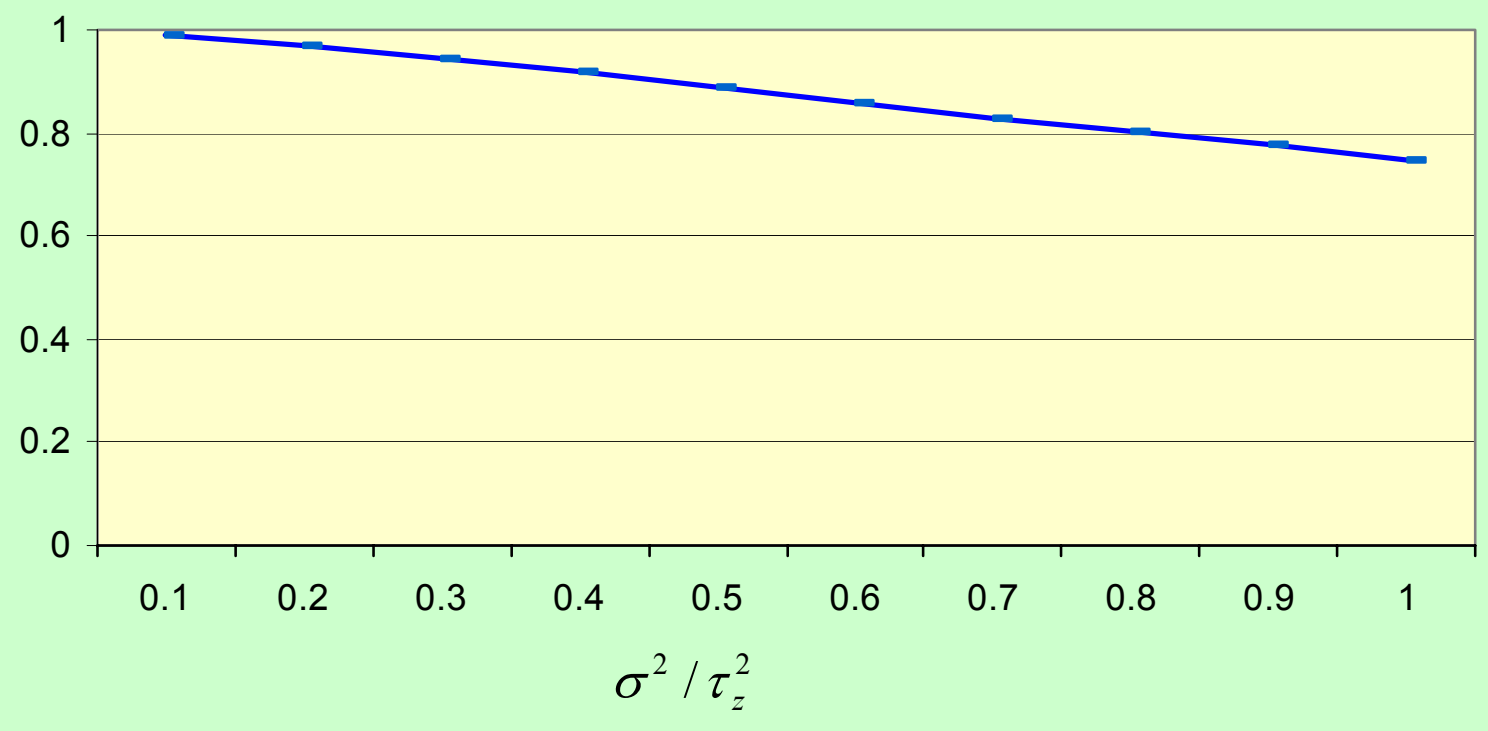


Figure 2a. Inflation Forecast Uncertainty Based on Survey Data

(Horizon Adjusted)

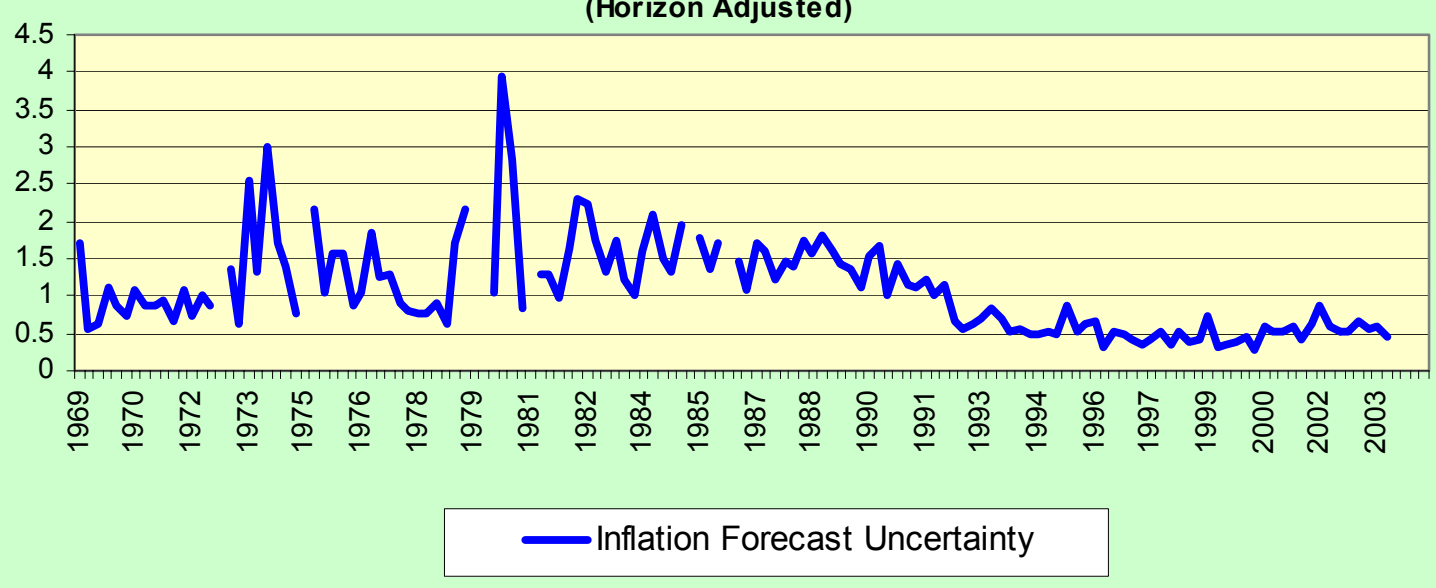

Figure 2b. Two Components of Inflation Forecast Uncertainty

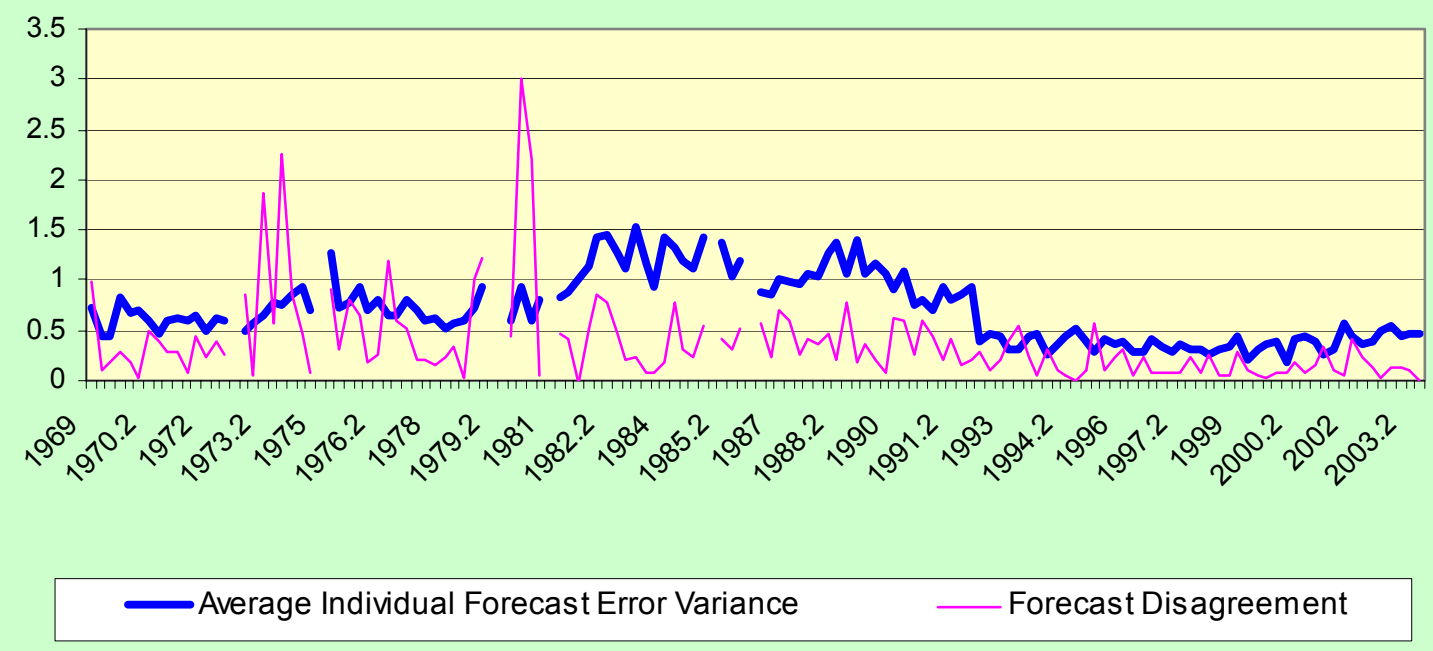


Figure 3a. Four-Quarter Ahead Forecast Uncertainty
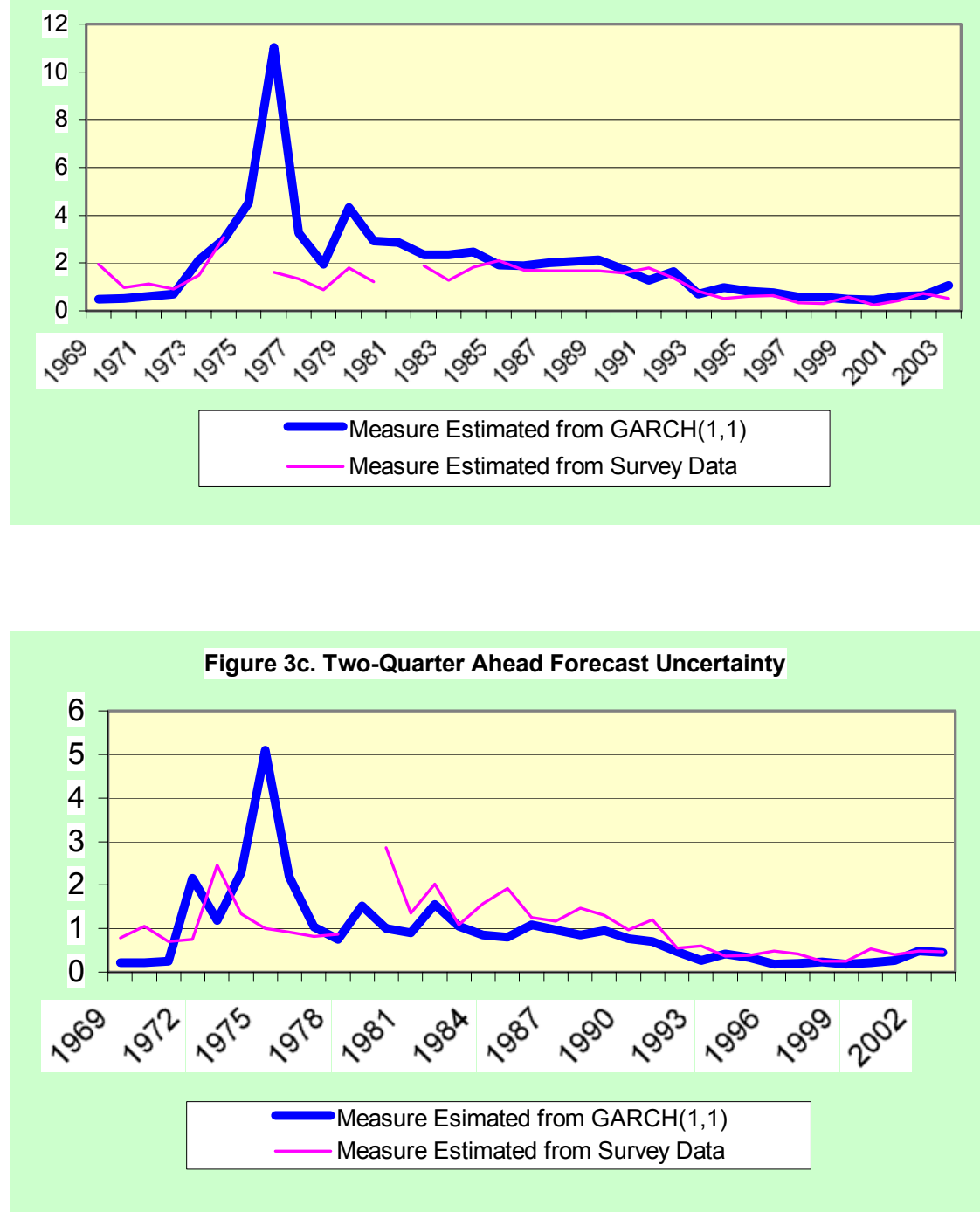

Figure 3b. Three-Quarter Ahead Forecast Uncertainty

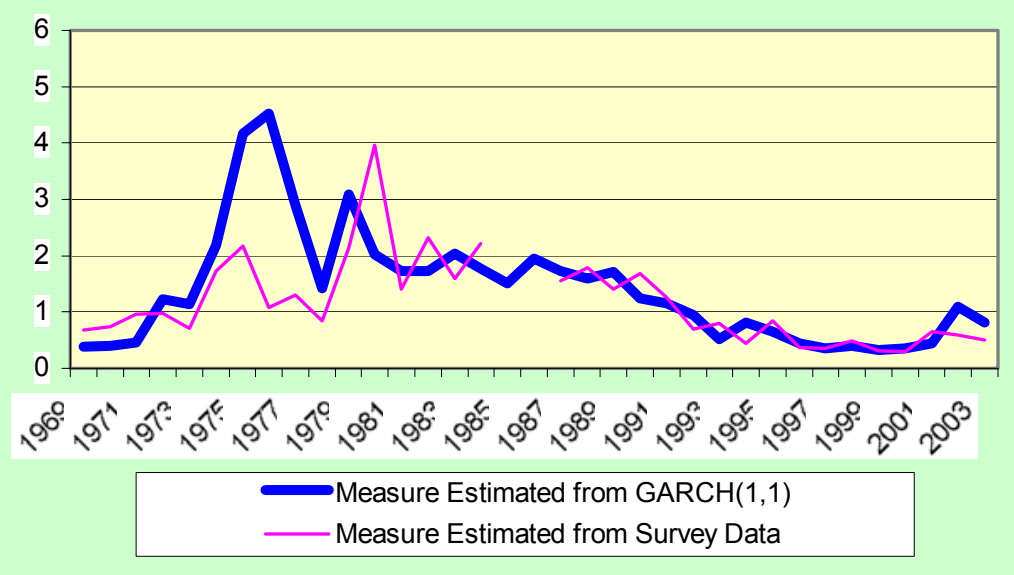

Figure 3d. One-Quarter Ahead Forecast Uncertainty

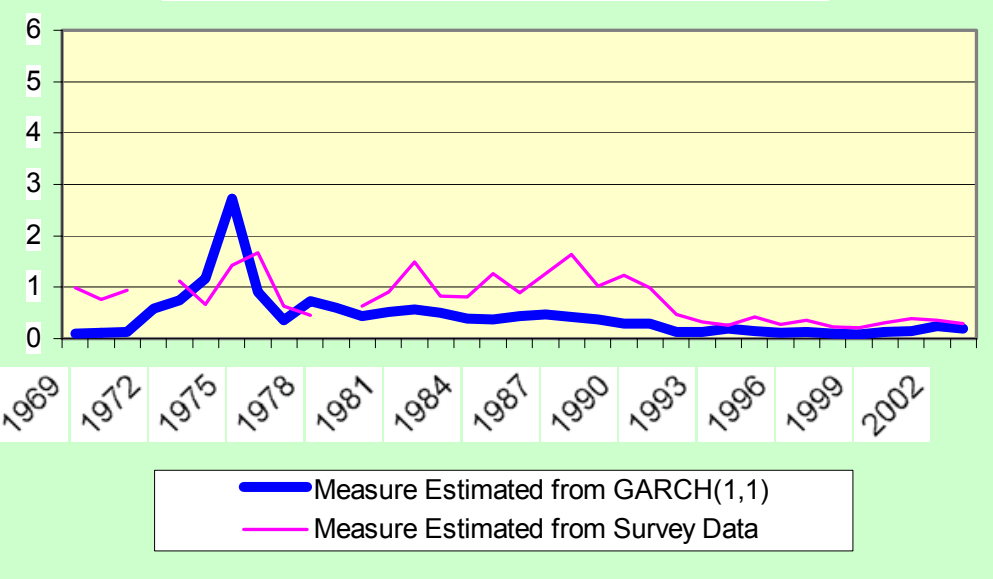


Figure 4a. Comparison of Point Forecasts Estimated from Time Series and Survey Data

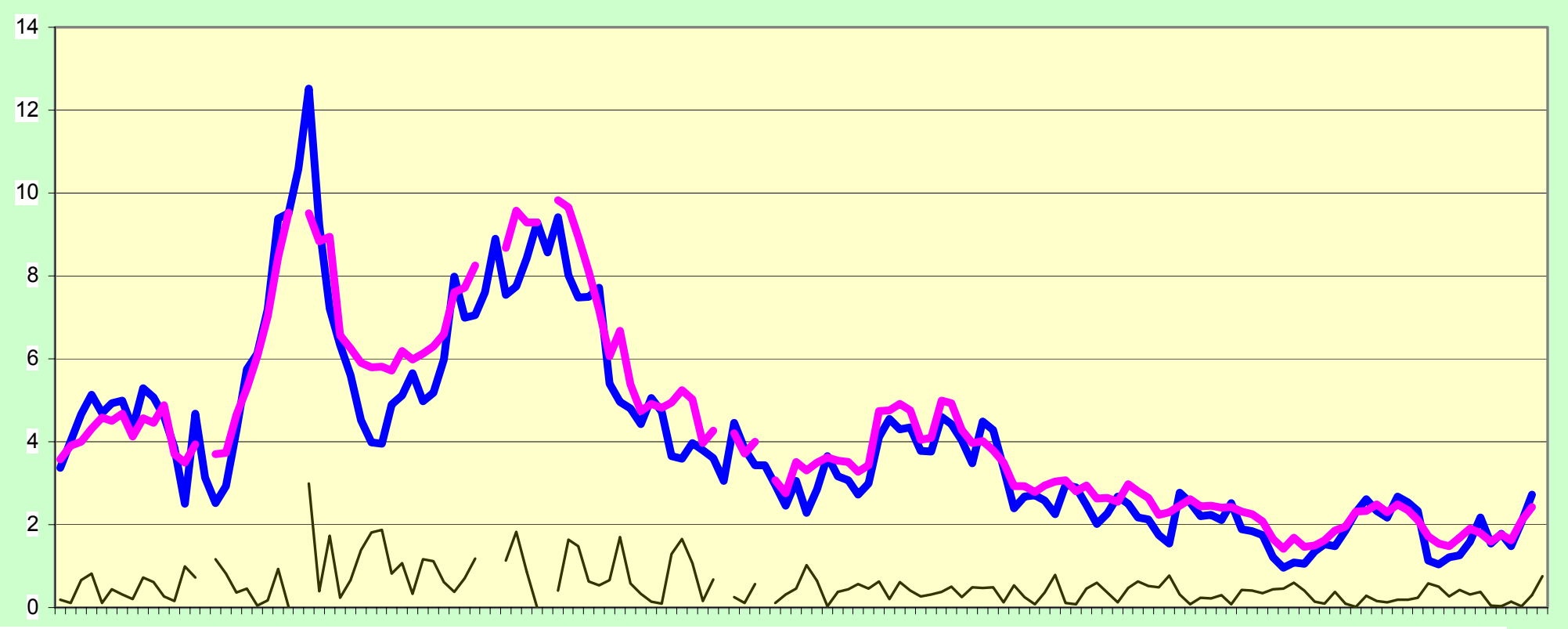

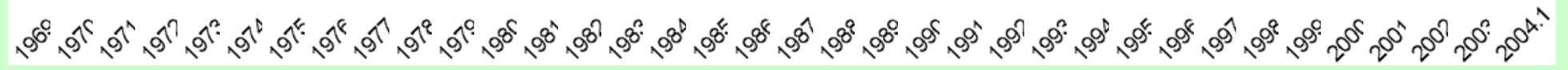

Point Forecast Estimated from GARCH(1,1)

Point Forecast Estimated from Survey Data

Difference Between Point Forecast Estimated from $\operatorname{GARCH}(1,1)$ and Survey Data 


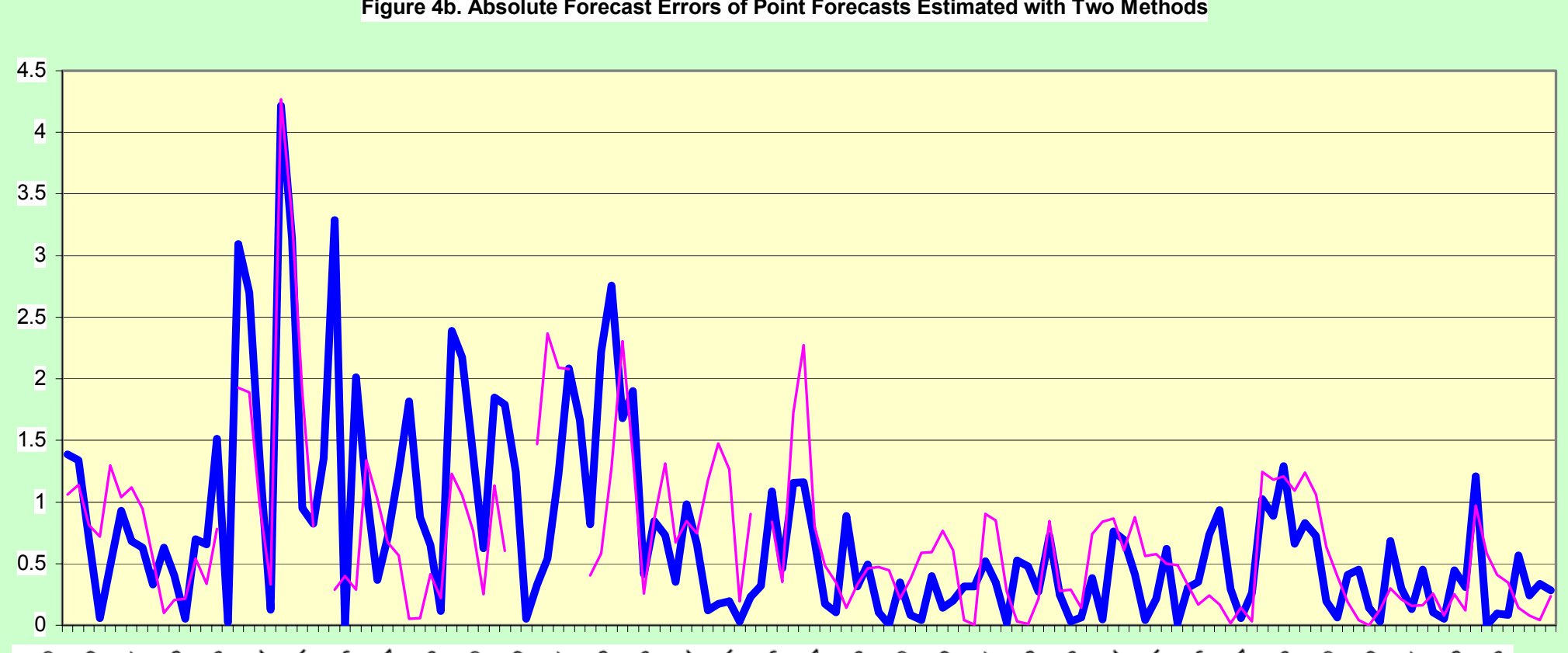


Figure Sa. Four-Quarter Ahead Forecast Uncertainty

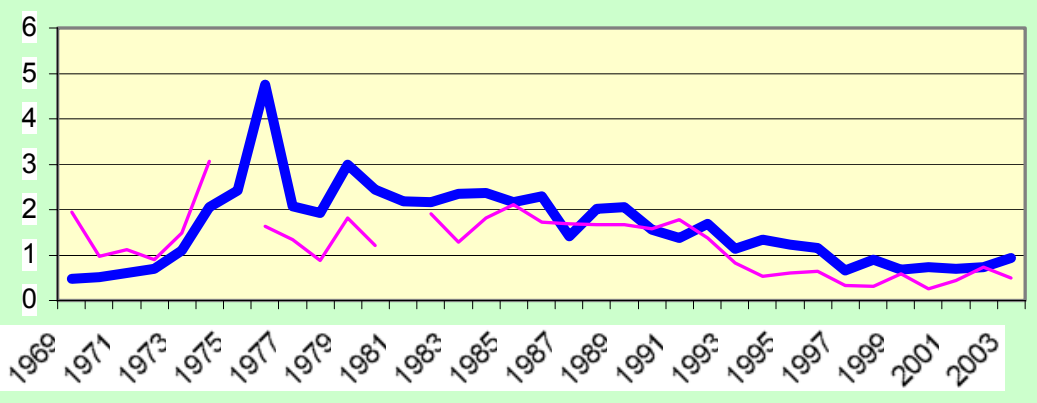

Measure Estimated from Modified GARCH $(1,1)$

Survey Measure

Figure Sc. Two-Quarter Ahead Forecast Uncertainty

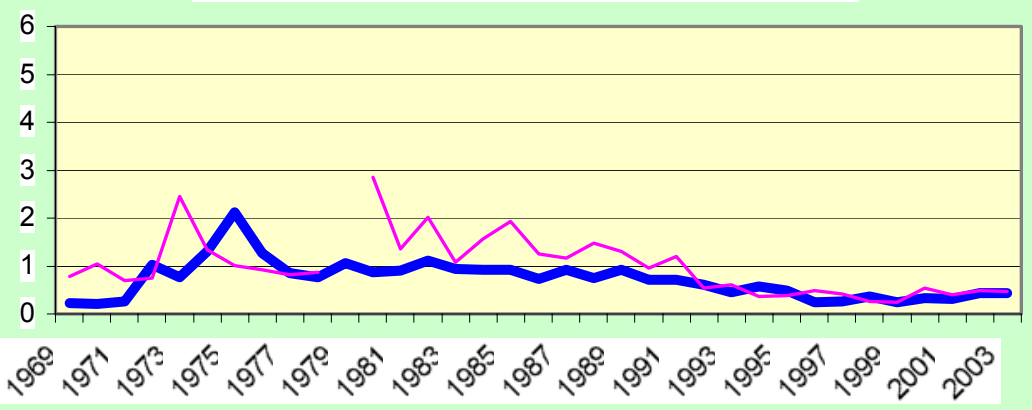
Measure Estimated from Modified GARCH$(1,1)$
Survey Measure
Figure Sb. Three-Quarter Ahead Forecast Uncertainty

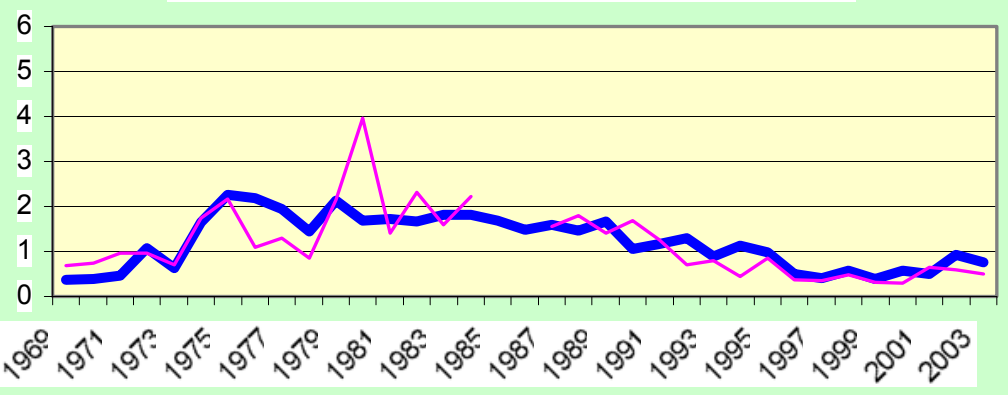

Measure Estimated from Modified GARCH $(1,1)$

Figure 5d. One-Quarter Ahead Forecast Uncertainty

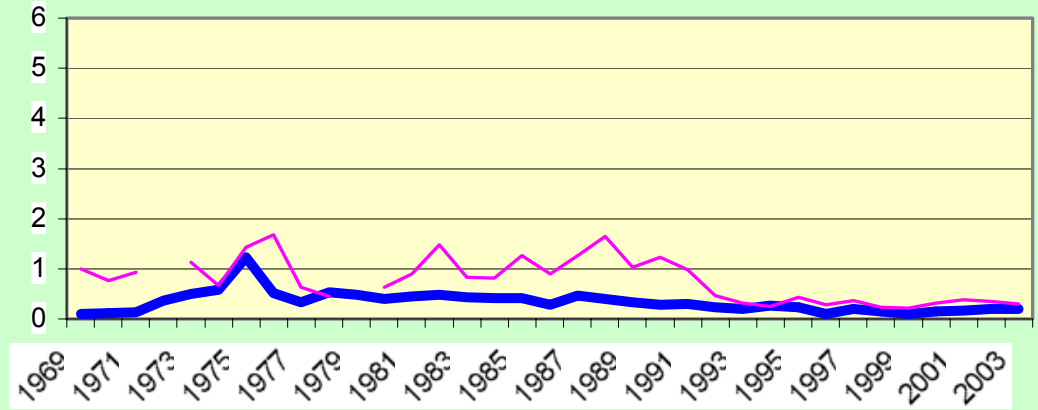
Measure Estimated from Modified GARCH $(1,1)$
Survey Measure

60 


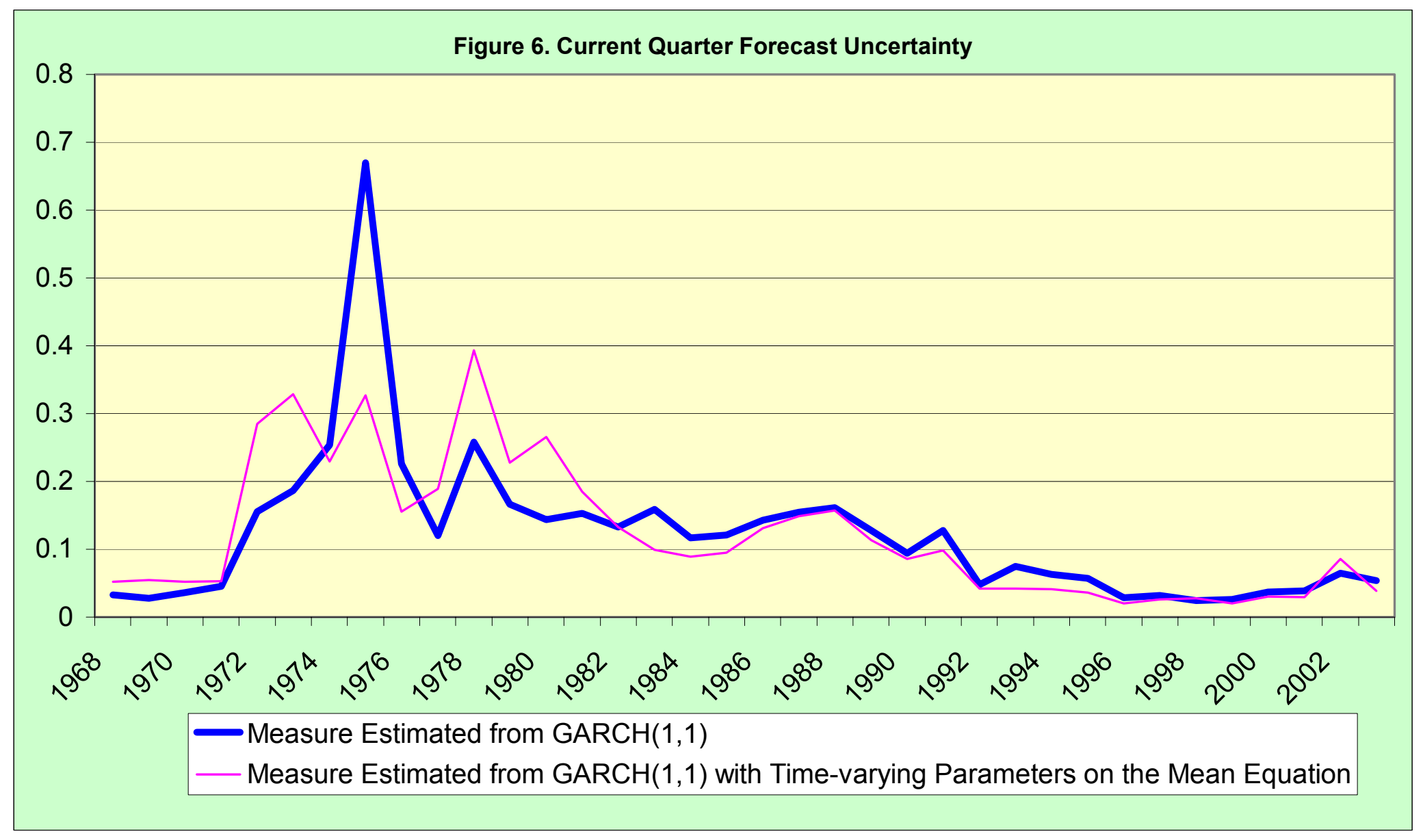

